\title{
New insights into the Manila clam and PAMPs interaction based on RNA-seq analysis of clam through in vitro challenges with LPS, PGN, and poly(l:C)
}

Kunyin Jiang ${ }^{1,2}$, Hongtao $\mathrm{Ni}^{1,2^{*}}$ (D), Dongdong $\mathrm{Li}^{1,2}$ and Xiwu Yan ${ }^{1,2}$

\begin{abstract}
Background: Manila clam (Ruditapes philippinarum) is a worldwide commercially important marine bivalve species. In recent years, however, microbial diseases caused high economic losses and have received increasing attention. To understand the molecular basis of the immune response to pathogen-associated molecular patterns (PAMPs) in R. philippinarum, transcriptome libraries of clam hepatopancreas were constructed at $24 \mathrm{~h}$ post-injection with Lipopolysaccharide (LPS), peptidoglycan (PGN), and polyinosinic-polycytidylic acid (poly(l:C)) and phosphatebuffered saline (PBS) control by using RNA sequencing technology (RNA-seq).

Results: A total of 832, 839, and 188 differentially expressed genes (DEGs) were found in LPS, PGN, and poly(l:C) challenge group compared with PBS control, respectively. Several immune-related genes and pathways were activated in response to the different PAMPs, suggesting these genes and pathways might specifically participate in the immune response to pathogens. Besides, the analyses provided useful complementary data to compare different PAMPs challenges in vivo. Functional enrichment analysis of DEGs demonstrated that PAMPs responsive signal pathways were related to apoptosis, signal transduction, immune system, and signaling molecules and interaction. Several shared or specific DEGs response to different PAMPs were revealed in $R$. philippinarum, including pattern recognition receptors (PRRs), antimicrobial peptides (AMPs), interferon-induced proteins (IFI), and some other immune-related genes were found in the present work.

Conclusions: This is the first study employing high throughput transcriptomic sequencing to provide valuable genomic resources and investigate Manila clam response to different PAMPs through in vivo challenges with LPS, PGN, and poly(l:C). The results obtained here provide new insights to understanding the immune characteristics of $R$. philippinarum response to different PAMPs. This information is critical to elucidate the molecular basis of $R$. philippinarum response to different pathogens invasion, which potentially can be used to develop effective control strategies for different pathogens.
\end{abstract}

Keywords: Manila clam (Ruditapes philippinarum), Immune response, RNA-seq, DEGs, Pathogen-associated molecular patterns (PAMPs)

\footnotetext{
* Correspondence: htnie@dlou.edu.cn

'College of Fisheries and Life Science, Dalian Ocean University, Dalian

116023, China

2Engineering Research Center of Shellfish Culture and Breeding in Liaoning

Province, College of Fisheries and Life Science, Dalian Ocean University,

Dalian 116023, China
}

(c) The Author(s). 2020 Open Access This article is licensed under a Creative Commons Attribution 4.0 International License, which permits use, sharing, adaptation, distribution and reproduction in any medium or format, as long as you give appropriate credit to the original author(s) and the source, provide a link to the Creative Commons licence, and indicate if changes were made. The images or other third party material in this article are included in the article's Creative Commons licence, unless indicated otherwise in a credit line to the material. If material is not included in the article's Creative Commons licence and your intended use is not permitted by statutory regulation or exceeds the permitted use, you will need to obtain permission directly from the copyright holder. To view a copy of this licence, visit http://creativecommons.org/licenses/by/4.0/ The Creative Commons Public Domain Dedication waiver (http://creativecommons.org/publicdomain/zero/1.0/) applies to the data made available in this article, unless otherwise stated in a credit line to the data. 


\section{Background}

Manila clam, Ruditapes philippinarum, is one of the most commercially important bivalves and reached over 4.2 million tons in 2017, which is widely distributed along the coast of China, Japan, and Korea [1]. R. philippinarum possesses many advantages as an aquaculture species, including wide salinity and temperature resistance, rapid growth, and pollution tolerance [2]. Nevertheless, $R$. philippinarum has been threatened with a huge challenge caused by pathogen invasion [3-5]. Pathogens can affect not only the development and survivorship of clams but also the quality and price of the product [6]. The majority of diseases in Manila clam are associated with Vibrio [7, 8] and Perkinsus [9, 10]. Diseases affecting $R$. philippinarum can result in mass mortality in aquaculture and cause large economic losses [11].

Although most bivalves lack a specific immune system, the innate response, which includes circulating hemocytes and multiple molecular effectors (PRRs, AMPs), appears to be an effective defense against external aggression [11]. Different receptors, regulators, and effectors, including pattern recognition receptors (PRRs), antimicrobial proteins (AMPs), and a variety of other molecules involved in agglutination, phagocytosis, and encapsulation, have been found in some Molluscs [12, 13]. In recent years, more and more research has been focused on the immune system of Molluscs [7, 14], and most of the research was focused on mussels, oyster, and scallop [15-17]. However, the available information on PRRs, AMPs, and immune-related signaling pathway of $R$. philippinarum is still limited.

In the past decades, the high-throughput RNA sequencing (RNA-seq) technique has been widely used to investigate molecular interactions between host and pathogen in Molluscs $[6,11]$. Some efforts have been made to enrich the clam gene database and to gain an in-depth understanding of the potential immune mechanism of $R$. philippinarum [11, 18]. Recently, gene expression profiles of $R$. philippinarum hemocytes stimulated with Perkinsus olseni trophozoites, zoospores, and extracellular products under different experimental conditions were analyzed with RNA-seq on an Illumina platform [10]. The 454 pyrosequencing technology was used to obtain hemocytes transcriptome after in vitro immunestimulated in the Manila clam, and a large number of immune-related genes were found that play important roles in the defense mechanisms of $R$. philippinarum [11]. Besides, transcriptional study in Manila clam in response to brown ring disease revealed that most changes in response to brown ring disease were tissue-specific, and a lot of candidate genes involved in microbe recognition and killing were identified [6]. Recently, the whole-genome of the Manila clam was assembled and annotated in our previous study [19], and the molecular basis of its adaptation to hypoxia, parasites and aerial exposure stress were analyzed [19-21]. However, the transcriptome analysis of response and defense against different pathogens or pathogen-associated molecular patterns (PAMPs) in Manila clam was still a largely unexplored landscape.

PAMPs, a class of conserved small molecular motif in microorganism, could be recognized by the PRRs of multicellular organisms and then activate innate immune response [22, 23]. Lipopolysaccharide (LPS), a well-characterized PAMP, is a component of the cell wall in Gram-negative bacteria [24]. It has been found that LPS could induce multiple innate immune responses in some Molluscs $[25,26]$. Peptidoglycan (PGN), a component of the bacterial cell wall, is extracted from both Gram-positive and Gram-negative bacteria [23]. In Crassostrea gigas, PGN was recognized by peptidoglycan recognition proteins (CgPGRPs) and CgTLR-6 [27, 28]. Polyinosinic-polycytidylic acid (poly(I: C)) is a kind of synthetic double-stranded RNA associated with viral infection [29]. It has been demonstrated that poly $(\mathrm{I}: \mathrm{C})$ could significantly up-regulate the expression of CgIFNLP, CgIFNR-3, and CgCaspase8-2 in C. gigas $[30,31]$. In bivalves, pattern recognition molecules (PRMs) could recognize PAMPs and trigger the innate immune response $[25,27,30,31]$. Hence, elucidating the immune response patterns and defense mechanisms of R. philippinarum against different PAMPs has important biological significance in the interpretation of the immune function of Manila clam.

In this study, we employed high throughput transcriptomic sequencing to investigate Manila clam response to different PAMPs through in vivo challenges with LPS, PGN, and poly(I:C). The hepatopancreas transcriptome of $R$. philippinarum after stimulated with three different PAMPs (LPS, PGN, and poly(I:C)) were analyzed to reveal the immune response of the Manila clam against LPS, PGN, and poly $(\mathrm{I}: \mathrm{C})$, and to elucidate the shared and specific immune-related genes in immune signaling pathways of Manila clam facing different PAMPs stress. This work sheds light on the molecular basis of Manila clam response to different PAMPs, and provides new insights into the immune signaling and pathogen defense responses of $R$. philippinarum.

\section{Results}

\section{Genome-guided transcriptome assembly}

A total of 533,660,306 raw reads were obtained, including 138,764,184 raw reads from the LPS treatment groups, 131,242,452 raw reads from the PGN treatment groups; $128,591,010$ raw reads from the poly(I:C) treatment groups, and 135,062,660 raw reads from the PBS control groups corresponding to the constructed 
libraries. After low-quality reads (quality scores < 20), short reads (length $<60 \mathrm{bp}$ ), and ambiguous nucleotides were removed, a total of $266,830,153$ clean reads were retained for further mapping and differential expression analysis. The clean reads were assembled into 35,919 unigenes with a mean length of $1681 \mathrm{bp}$, a minimum length of $122 \mathrm{bp}$, and a maximum length of $64,604 \mathrm{bp}$. Besides, 8266 novel genes were annotated in this study. Summarized trimming statistics and the number of sequenced reads per sample was shown in Additional file 1. The RNA sequencing data has been submitted to the NCBI SRA database (Accession number: PRJNA616201). Density distribution of expression level based on $\log 10$ (FPKM) in each library was exhibited in Additional file 2, which showed that LPS, PGN, and poly(I:C) groups were similar, while the PBS control group library was different with others three groups.

\section{Detection of differentially expressed genes}

A total of 1859 DEGs were identified from three PAMPs groups (LPS, PGN, and poly(I:C)) compared with the PBS group. The lowest number of DEGs (188) was found in the poly(I:C) group, while 832 and 839 DEGs were found in the LPS and PGN group, respectively. Of those DEGs, 635 up-regulated and 197 down-regulated in LPS group, 520 up-regulated and 319 down-regulated in PGN group and 86 up-regulated and 102 downregulated in poly $(\mathrm{I}: \mathrm{C})$ group were identified compared with PBS control group, respectively (Fig. 1). The number of up-regulated genes were significantly higher than the down-regulated genes in LPS and PGN group.

\section{Genes activated by LPS, PGN, and poly(I:C)}

To uncover PAMPs responsive genes activated by LPS, PGN, or poly(I:C), the transcripts that passed the cut-off criteria ( $\geq 2$ fold change, $P<0.05$ ) were further analyzed and the known or putative function were shown in Table 1. A hierarchical clustering figure exhibited the global expression profiles of DEGs in each library (Fig. 2). It shows that the LPS group firstly clustered with PGN group then with the poly(I:C) group. The most upregulated genes were defensin-B $(D E F)$ and mucin-like protein $(M U C L)$ in LPS group (26.8- and 25.5-fold, respectively), $D E F$ and E3 ubiquitin-protein ligase (RNF213) in PGN group (26.3- and 25.7-fold, respectively) and cadherin EGF LAG seven-pass G-type receptor (CELSR) and Complement $\mathrm{Clq}$ tumor necrosis factor-related protein $(C T R P)$ in poly(I:C) group (25.5fold and 24.8-fold, respectively) (Table 1). Some pivotal PRMs directly involved in the innate immune system to reconigize PAMPs were significantly up- or downregulated ( $\geq 5$ fold) including peptidoglycan recognition protein $(P G R P)$, toll-like receptor $(T L R)$, ficolin $(F C N)$, collectin $(C L)$, complement c1q-like protein $(C 1 q L)$, Complement component C3 (C3), calmodulin (CALM), cysteine-rich protein 2 (CRIP2), fibrinogen-like protein $(F R E P)$, serine protease inhibitor $(S P I)$, interferon alphainducible protein (IFI), heat shock $70 \mathrm{kDa}$ protein (HSP70), and etc. (Table 1).

\section{Comparison of transcriptome profiles elicited by different PAMPs}

As showing in Fig. 3a and c, the DEGs in response to poly(I:C) were significantly less than that in response to LPS or PGN in R. philippinarum, while the number of DEGs in LPS and PGN groups were similar. A total of 255 genes were differentially expressed ( $\geq 2$ fold change) in response to LPS challenge, which were also found in the DEGs of PGN challenge group, for example, Cathelicidin $(C A T H)$, scavenger receptor cysteine-rich $(S R C R)$, IgGFc-binding protein (FCGBP), low affinity immunoglobulin epsilon Fc receptor (FCGR), Cell number

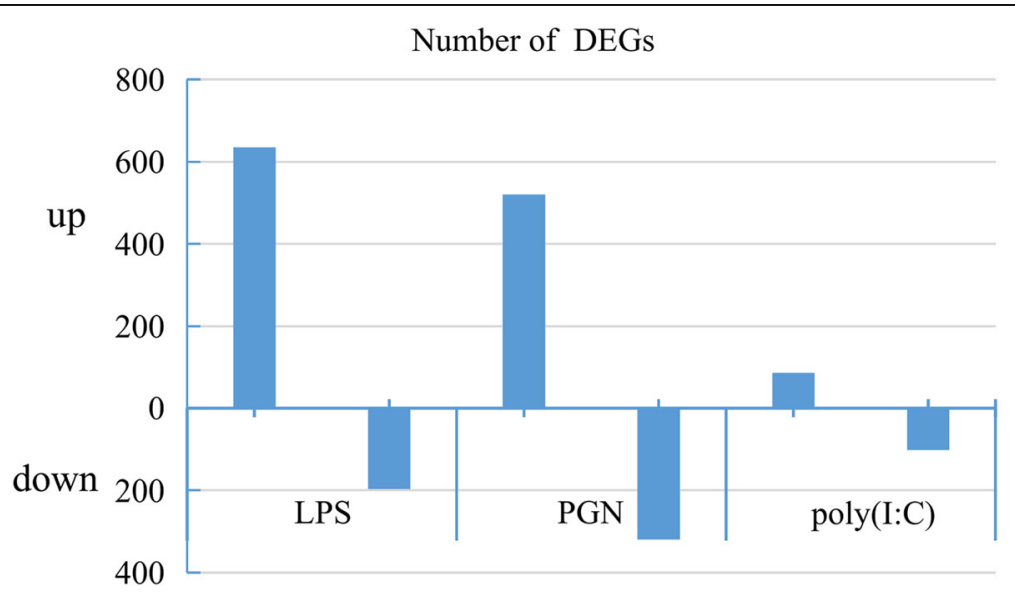

Fig. 1 The number of up- and down-regulated DEGs in the hepatopancreas of R. philippinarum that was injected with LPS, PGN, poly(l:C). The DEGs number of LPS and PGN group was similar and was higher than the poly(l:C) group 
Table 1 The shared and specific DEGs in Manila clam post injected with LPS, PGN and poly (I:C)

\begin{tabular}{|c|c|c|c|c|c|}
\hline \multirow[t]{2}{*}{ Abbreviations } & \multirow[t]{2}{*}{ Gene name } & \multirow[t]{2}{*}{ ID } & \multicolumn{3}{|c|}{ Log2 Fold change } \\
\hline & & & LPS vs PBS & PGN vs PBS & $\begin{array}{l}\text { poly }(I: C) \text { vs } \\
\text { PBS }\end{array}$ \\
\hline \multicolumn{6}{|c|}{ DEGs shared by all three group } \\
\hline MUCL & Mucin-like protein & evm.model.xfSc0001058.9 & 25.53 & 24.04 & 14.51 \\
\hline$|F|$ & Interferon alpha-inducible protein 27 & evm.model.xfSc0000070.25 & 10.58 & 11.38 & 3.46 \\
\hline CTRP3 & Complement $\mathrm{Clq}$ tumor necrosis factor-related protein 3 & evm.model.xfSc0000125.38 & 10.34 & 9.58 & 24.80 \\
\hline Perlucin & Perlucin & Novel03513 & 10.15 & 8.12 & 8.95 \\
\hline CALM & Calmodulin & evm.model.xfSc0002618.1 & 6.73 & 6.67 & 2.56 \\
\hline LC & Snaclec coagulation factor IX & evm.model.xfSc0030245.1 & 6.60 & 5.24 & 22.74 \\
\hline$D E F$ & Defensin & Novel05650 & 4.90 & 8.49 & 11.01 \\
\hline$P G R P$ & Peptidoglycan recognition protein & Novel01511 & 4.73 & 2.75 & 8.01 \\
\hline ITGA & Integrin alpha-4 & Novel02605 & 3.64 & 6.31 & 5.72 \\
\hline$|F|$ & Interferon alpha-inducible protein 27 like protein 1 & evm.model.xfSc0000188.23 & -23.45 & -4.62 & -5.44 \\
\hline GBP1 & Interferon-induced guanylate-binding protein 1-like & Novel04750 & -22.62 & -23.78 & -23.09 \\
\hline GTPA & GTP-binding protein A & evm.model. Sc0000135.12 & -9.97 & -9.08 & -9.72 \\
\hline RNF213 & E3 ubiquitin-protein ligase RNF213 & evm.model.xfSc0002255.2 & -9.80 & -5.56 & -13.83 \\
\hline NPC2 & Epididymal secretory protein E1 & evm.model.xfSc0001403.6 & -9.46 & -10.00 & -9.22 \\
\hline HCK & Tyrosine-protein kinase HCK & evm.model. Sc0000062.24 & -8.90 & -4.42 & -22.62 \\
\hline ITGB & Integrin beta-like protein A & Novel03831 & -7.15 & -11.42 & -5.63 \\
\hline Ubr2 & E3 ubiquitin-protein ligase & evm.model.xfSc0002514.1 & -6.90 & -5.70 & -10.69 \\
\hline HAAF & Hemagglutinin/amebocyte aggregation factor & Novel05234 & -6.71 & -2.32 & -2.01 \\
\hline$L R / G 1$ & Leucine-rich repeats and immunoglobulin-like domains protein1 & evm.model. Sc0000048.11 & -6.16 & -4.85 & -4.57 \\
\hline Ubri & E3 ubiquitin-protein ligase & Novel07244 & -6.06 & -5.34 & -6.68 \\
\hline DAPK1 & Death-associated protein kinase 1 & evm.model.xfSc0000378.13 & -4.94 & -6.66 & -5.17 \\
\hline GBP1 & Interferon-induced guanylate-binding protein 1 & Novel02352 & -4.67 & -5.99 & -9.27 \\
\hline \multicolumn{6}{|c|}{ DEGs shared by LPS and PGN group } \\
\hline$D E F B$ & Defensin-B & evm.model.xfSc0000150.16 & 26.78 & 26.33 & \\
\hline $\mathrm{CDH} 23$ & Cadherin-23 & evm.model.xfSc0000164.15 & 10.73 & 10.79 & \\
\hline HEXB & Beta-hexosaminidase subunit beta & evm.model.xfSc0006767.1 & 8.71 & 9.95 & \\
\hline NEKT & Serine/threonine-protein kinase Nek7-like & Novel08087 & 8.22 & 8.64 & \\
\hline CALM & Calmodulin & evm.model.xfSc0000392.15 & 8.14 & 8.33 & \\
\hline$\angle R 74 A$ & Leucine-rich repeat-containing protein $74 \mathrm{~A}$ & evm.model.xfSc0000002.29 & 7.56 & 8.65 & \\
\hline CRIP2 & Cysteine-rich protein 2 & evm.model.xfSc0001224.15 & 5.90 & 6.92 & \\
\hline GM2 & Ganglioside GM2 activator & evm.model.xfSc0000725.12 & 5.86 & 6.19 & \\
\hline Nimik & Serine/threonine-protein kinase NIM1 & evm.model.xfSc0000017.35 & 5.53 & 6.12 & \\
\hline$L R 74 A$ & Leucine-rich repeat-containing protein $74 \mathrm{~A}$ & evm.model.xfSc0000002.30 & 5.51 & 5.36 & \\
\hline TEX14 & Serine/threonine-protein kinase TEX14 & evm.model.xfSc0000164.11 & 5.20 & 5.64 & \\
\hline CNR3 & Cell number regulator 3 & evm.model.xfSc0001389.2 & 4.97 & 4.89 & \\
\hline CSA1 & Cell surface antigen $\mathrm{I} / \|$ & evm.model.xfSc0000741.1 & 4.80 & 4.25 & \\
\hline TBA3 & Tubulin alpha-3 chain & evm.model.xfSc0000328.3 & 4.79 & 4.76 & \\
\hline CATH & Cathelicidin-B1 & evm.model.xfSc0001753.3 & 4.65 & 4.09 & \\
\hline$S R C R$ & Scavenger receptor cysteine-rich & evm.model.xfSc0004748.1 & 4.54 & 4.30 & \\
\hline LSS & Lysostaphin & evm.model.xfSc0000599.7 & 4.35 & 4.73 & \\
\hline FCGR & Low affinity immunoglobulin epsilon Fc receptor-like & Novel02789 & 3.78 & 7.03 & \\
\hline
\end{tabular}


Table 1 The shared and specific DEGs in Manila clam post injected with LPS, PGN and poly (I:C) (Continued)

\begin{tabular}{ll}
\hline Abbreviations & Gene name \\
& \\
\hline DYH8 & Dynein heavy chain 8 \\
FCGBP & lgGFc-binding protein \\
C1qL & Complement C1q-like protein 4 \\
CTRP3 & Complement C1q tumor necrosis factor-related protein 3 \\
FA10 & Coagulation factor X \\
CTL & C-type lectin \\
DEGS shared by LPS and poly(l:C) group \\
C1qL & Complement C1q-like protein 4 \\
CELSR1 & Cadherin EGF LAG seven-pass G-type receptor 1 \\
THAP12 & 52 kDa repressor of the inhibitor of the protein kinase-like \\
HSP70A & Heat shock 70 kDa protein 12A \\
C3 & Complement component C3 \\
TGFBI & Transforming growth factor-beta-induced protein ig-h3 \\
HSP70 & Heat shock 70 kDa protein \\
CL12 & Collectin-12 \\
ADGRE1 & Adhesion G protein-coupled receptor E1
\end{tabular}

DEGs shared by PGN and poly(l:C) group

$\begin{array}{ll}\text { RNF213 } & \text { E3 ubiquitin-protein ligase RNF213 } \\ \text { MMR1 } & \text { Macrophage mannose receptor 1 } \\ \text { PGRP } & \text { Peptidoglycan recognition protein } \\ \text { TLR2 } & \text { Toll-like receptor 2 } \\ \text { GBP1 } & \text { Interferon-induced guanylate-binding protein 1-like } \\ \text { Casp3 } & \text { Caspase-3 } \\ \text { FAS1 } & \text { Fasciclin-1-like isoform X2 } \\ \text { DD2 } & \text { Discoidin-2 } \\ \text { LTL } & \text { L-type lectin }\end{array}$

Secific DEGs of LPS group

$\begin{array}{ll}\text { SPI } & \text { Serine protease inhibitor Cvsi-2-like } \\ \text { FCN1 } & \text { Ficolin-1 } \\ \text { DYLC6 } & \text { Dynein light chain LC6 } \\ \text { HSP70B } & \text { Heat shock } 70 \mathrm{kDa} \text { protein 12B } \\ \text { IMSP3 } & \text { Insoluble matrix shell protein 3 } \\ \text { IMSP3 } & \text { Insoluble matrix shell protein 3 } \\ \text { IMSP1 } & \text { Insoluble matrix shell protein 1 } \\ \text { PAR14 } & \text { Poly [ADP-ribose] polymerase 14 } \\ \text { PO } & \text { Peroxidase-like protein }\end{array}$

$\begin{array}{lll}\text { evm.model. Sc0000012.11 } & 3.68 & 5.54 \\ \text { evm.model.xfSc0000000.12 } & -9.374 & -8.78 \\ \text { evm.model.xfSc0010046.1 } & -7.39 & -5.44 \\ \text { evm.model.xfSc0001711.7 } & -2.30 & -10.37 \\ \text { evm.model.xfSc0000836.3 } & -2.17 & -8.98 \\ \text { evm.model.xfSc0000570.24 } & 1.50 & -2.74\end{array}$

\begin{tabular}{llll} 
evm.model.xfSc0000421.27 & 8.80 & & 23.06 \\
evm.model.xfsc0000749.1 & 8.27 & & 25.47 \\
Novel02627 & 8.06 & & 10.93 \\
evm.model.xfSc0002157.2 & 4.54 & & 4.51 \\
Novel05951 & 2.99 & & 3.61 \\
evm.model.xfSc0003432.2 & -10.37 & & -10.09 \\
evm.model.xfSc0000048.21 & -6.45 & & -7.55 \\
evm.model.xfSc0000743.13 & -5.99 & & 1.37 \\
evm.model.xfSc0003876.2 & -5.77 & & -1.13 \\
& & & \\
Novel00498 & & 25.70 & 13.53 \\
evm.model.xfSc0000262.8 & & 5.43 & 4.06 \\
evm.model.xfSc0000442.9 & & 4.39 & 1.25 \\
Novel05810 & & 3.13 & 8.62 \\
Novel03779 & & -25.11 & -24.42 \\
Novel00341 & & -6.27 & -3.42 \\
Novel05543 & & -4.89 & -9.62 \\
Novel04420 & -4.57 & -25.07 \\
evm.model.xfSc0004145.1 & -3.01 & -10.70 \\
\hline & & &
\end{tabular}

$\begin{array}{ll}\text { Novel07619 } & 12.47 \\ \text { evm.model.xfSc0000006.29 } & 9.42 \\ \text { evm.model.xfSc0000411.8 } & 9.33 \\ \text { evm.model.xfSc0003908.3 } & 9.10 \\ \text { evm.model.xfSc0000186.20 } & 8.98 \\ \text { evm.model. Sc0000176.1 } & 5.71 \\ \text { evm.model.xfSc0000058.28 } & 4.40 \\ \text { evm.model.xfSc0003656.1 } & -24.49 \\ \text { evm.model.xfSc0000759.9 } & -4.32\end{array}$

Specific DEGs of PGN group

$\begin{array}{ll}\text { HSP7OB } & \text { Heat shock } 70 \mathrm{kDa} \text { protein } 12 \mathrm{~B} \\ \text { HAAF } & \text { Hemagglutinin/amebocyte aggregation factor } \\ \text { PYG } & \text { Glycogen phosphorylase } \\ \text { HSP7OB } & \text { Heat shock protein } 70 \text { B2 } \\ \text { DYH8 } & \text { Dynein heavy chain } 8\end{array}$

$\begin{array}{ll}\text { evm.model.xfSc0002250.4 } & 22.30 \\ \text { Novel08154 } & 10.22 \\ \text { evm.model.xfSc0001103.7 } & 8.58 \\ \text { evm.model.xfSc0000005.7 } & 8.87 \\ \text { evm.model. Sc0000012.12 } & 5.87\end{array}$


Table 1 The shared and specific DEGs in Manila clam post injected with LPS, PGN and poly (I:C) (Continued)

\begin{tabular}{|c|c|c|c|c|c|}
\hline \multirow[t]{2}{*}{ Abbreviations } & \multirow[t]{2}{*}{ Gene name } & \multirow[t]{2}{*}{ ID } & \multicolumn{3}{|c|}{ Log2 Fold change } \\
\hline & & & LPS vs PBS & PGN vs PBS & $\begin{array}{l}\text { poly }(1: C) \text { vs } \\
\text { PBS }\end{array}$ \\
\hline TLR1 & Toll-like receptor 1 & evm.model.xfSc0000331.15 & & -7.86 & \\
\hline PAR14 & Poly [ADP-ribose] polymerase 14 & evm.model.xfSc0001993.2 & & -6.92 & \\
\hline $\operatorname{COBA}$ & Collagen alpha-1(VIII) chain & evm.model.xfSc0000095.25 & & -4.87 & \\
\hline RNF213 & E3 ubiquitin-protein ligase RNF213 & evm.model.xfSc0003464.1 & & -3.61 & \\
\hline \multicolumn{6}{|c|}{ Specific DEGs of poly(l:C) group } \\
\hline Siglec & Sialic acid-binding lectin & Novel06415 & & & 24.00 \\
\hline FCGR & Low affinity immunoglobulin epsilon Fc receptor & evm.model.xfSc0000236.23 & & & 23.86 \\
\hline$|F|$ & Interferon-induced protein 44-like & evm.model.xfSc0004748.1 & & & 11.07 \\
\hline FREP & Fibrinogen-like protein A & evm.model.xfSc0000316.4 & & & 10.07 \\
\hline$|F|$ & Interferon-inducible GTPase 5-like & Novel03245 & & & 5.10 \\
\hline IFI44 & Interferon-induced protein 44 & evm.model.xfSc0003071.3 & & & -25.60 \\
\hline PAR12 & Poly [ADP-ribose] polymerase 12 & evm.model.xfSc0000879.10 & & & -24.32 \\
\hline CAPRIN2 & Caprin-2 & evm.model.xfSc0001617.5 & & & -9.18 \\
\hline$\angle R R$ & Leucine-rich repeat protein, putative & Novel03097 & & & -5.82 \\
\hline
\end{tabular}

regulator $3(C N R)$. Besides, 33 DEGs in the LPS challenge group were also found in poly(I:C) challenge group, such as CL, CELSR1, transforming growth factorbeta-induced protein (TGFBI), and adhesion $\mathrm{G}$ proteincoupled receptor (ADGRE1). PGN challenge group and poly(I:C) challenge group shared 51 DEGs involved in PAMPs detection, including TLR, L-type lectin $(L T L)$, macrophage mannose receptor 1 (MMR1), and discoidin-2 (DD2). Besides, there are 22 DEGs (fold change $>2$ ) shared by all of the PAMPs group, such as PGRP, Perlucin, C1qL, CTRP3, DEF, IFI, and deathassociated protein kinase (DAPK). (Fig. 3a, Table 1).

\section{GO and KEGG enrichment analysis of DEGs}

GO enrichment analysis was performed for the DEGs of each group. A total of 1384, 1452, and 637 terms were significantly enriched in LPS, PGN, and poly(I:C) group, respectively. The proportion of biological process, molecular function, cell component in those three group was similar (Fig. 4a-c). As showing in Fig. 4d-f, the top GO terms (the most enriched GO terms) shared by those group were primarily involved in immune response (GO:0006955), response to host immune response (GO:0052572), pattern binding (GO:0001871), positive regulation of GTPase activity (GO:0043547) and regulation of cell death (GO:0010941). In addition, some transcripts were clustered into the immune-related categories, such as response to stress (GO:0006950), response to bacterium (GO:0009617), response to wounding (GO:0009611), bacteriocin immunity (GO: 0030153), wound healing (GO:0042060), and defense response to bacterium (GO:0042742). Those transcripts are likely to be involved in response to pathogens infection of $R$. philippinarum.

KEGG pathway enrichment analysis of DEGs was conducted to detect significantly altered pathways in each group. A total of 28, 41, and 21 pathways were significantly enriched in LPS, PGN, and poly(I:C) group, respectively $(P<0.05)$ (Fig. $3 \mathrm{~b})$. These pathways were primarily involved in apoptosis, signal transduction, immune system, and signaling molecules and interaction (Table 2). Furthermore, some enriched immune-related pathways were shared by multiple PAMPs groups, such as Platelet activation (map 04611) and Focal adhesion (map 04510) (shared by LPS, PGN, and poly(I:C) group), Phagosome (map 04145) (shared by LPS and poly(I:C) group), ECM-receptor interaction (map 04512) and Complement and coagulation cascades (map 04610) (shared by PGN poly(I:C) group), Cell cycle (map 04110), p53 signaling pathway (map 04115), cGMP-PKG signaling pathway (map 04022), and Calcium signaling pathway (map 04020), (shared by LPS and PGN group) (Table 2). Besides, some specific immunerelated pathways enriched by DEGs also were identified, such as Lysosome (map 04142) (Fig. 5) and Regulation of actin cytoskeleton (map 04810) in LPS challenge group, NOD-like receptor signaling pathway (map 04621) (Fig. 6), Dopaminergic synapse (map 04728), Inflammatory mediator regulation of TRP channels (map 04750), and Melanogenesis (map 04916) in PGN challenge group; Cell adhesion molecules (CAMs) (map 04514) and B cell receptor signaling pathway (map 04662) in poly(I:C) challenge group (Additional file 3 ). 


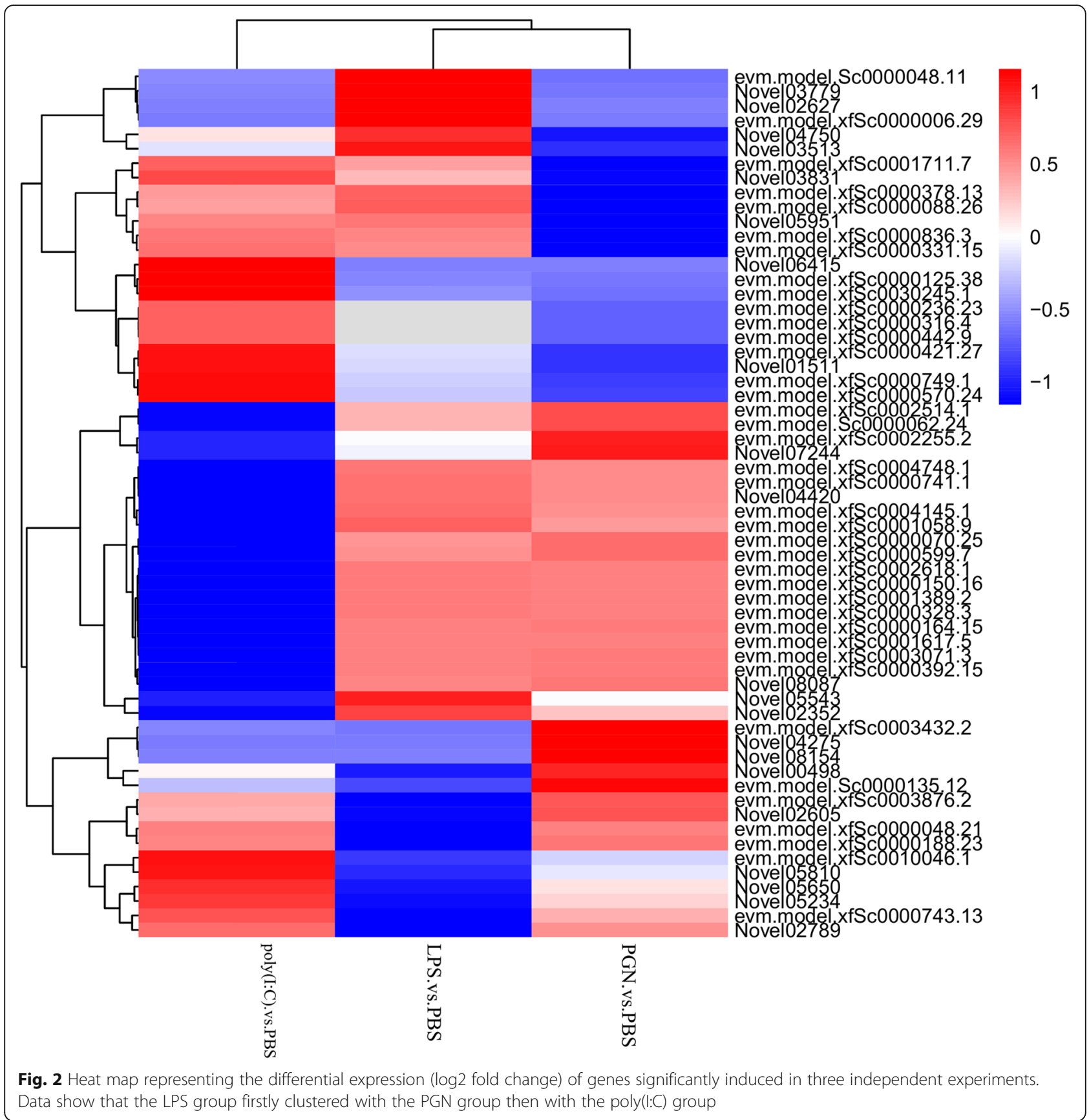

\section{Validation of gene expression profiles using the} quantitative real-time PCR

To validate the accuracy of RNA-seq results, we select both shared and specific immune-related genes that were differentially expressed in response to LPS, PGN, and poly(I:C) to perform the quantitative real-time PCR (qPCR) analysis. The specific primers of those genes were listed in Additional file 4. The fold change detected by qPCR was compared with that detected by RNA-Seq expression analysis (Fig. 7). As is shown in Fig. 7, nearly all of those DEGs shared the same trends in LPS, PGN, and poly(I:C) groups. In general, PAMPs responsive genes identified with quantitative real-time PCR experiments were consistent with the results of the Illumina sequencing analysis, indicating the accuracy of the RNAseq expression analysis.

\section{Discussion}

This study provides the first genome-based transcriptome analysis in the hepatopancreas of $R$. philippinarum under three different PAMPs challenge (LPS, PGN, and poly(I:C)). Due to the availability of $R$. 


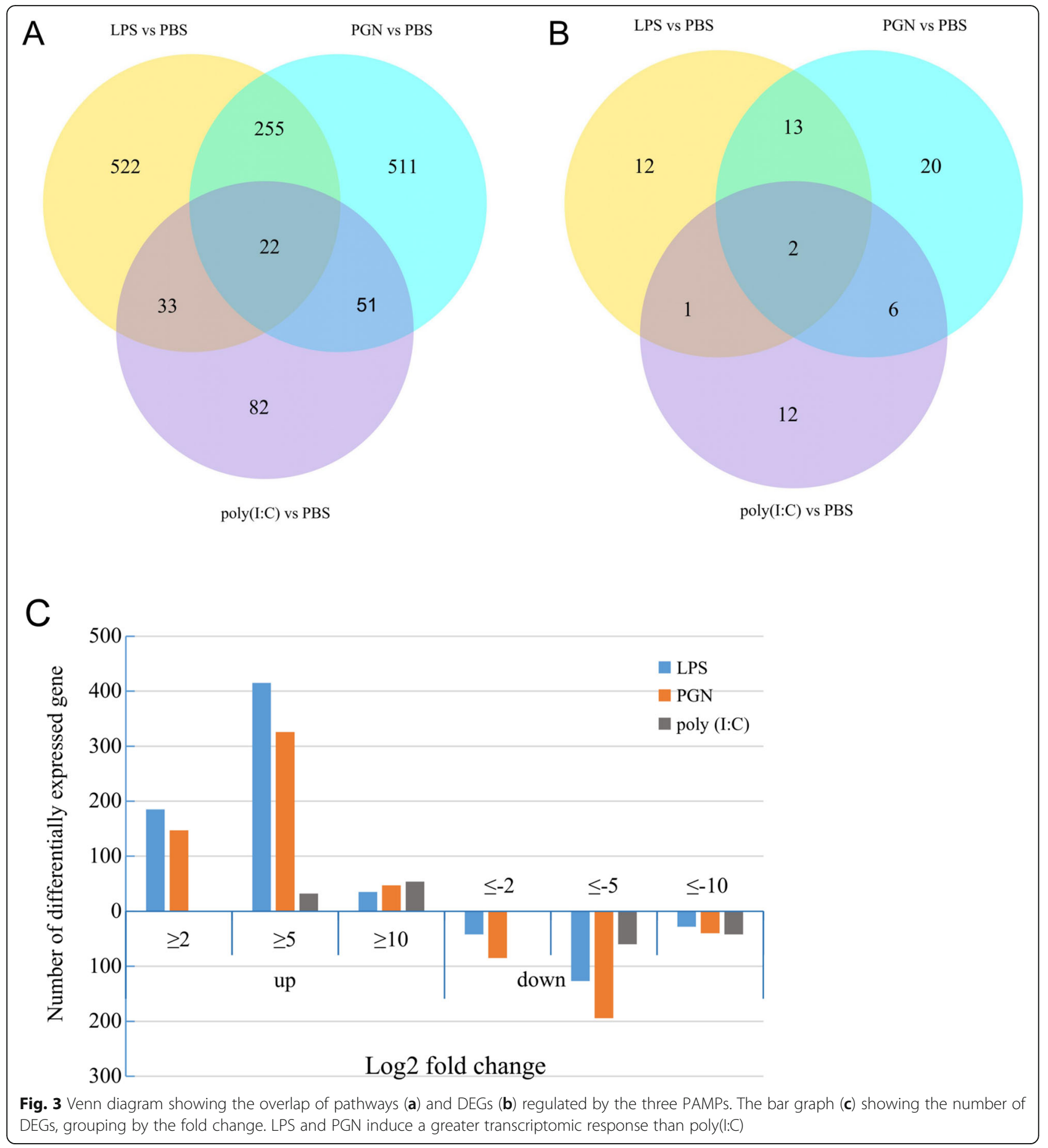

philippinarum whole-genome sequence date [21], enable us could effectively extract reads that mapped to exons, avoid problems caused by intron-mapped reads [32], and found many novel genes which were not annotated in $R$. philippinarum genome. To better understand the innate immune system of $R$. philippinarum response to PAMPs challenge and to uncover the difference of Manila clam response to different
PAMPs, the immune-related pathways, and genes that differentially expressed in different PAMPs challenge groups were analyzed. In the present study, several PRMs that are important in detecting PAMPs were identified, including the FREP, C1qL, FCN, TLR, PGRP, Perlucin, MMR1, C-type lectin (CTL), CL, LTL, $S R C R$, and sialic acid-binding lectin (Siglec) (Table 1), most of which could activate innate immune response 
A
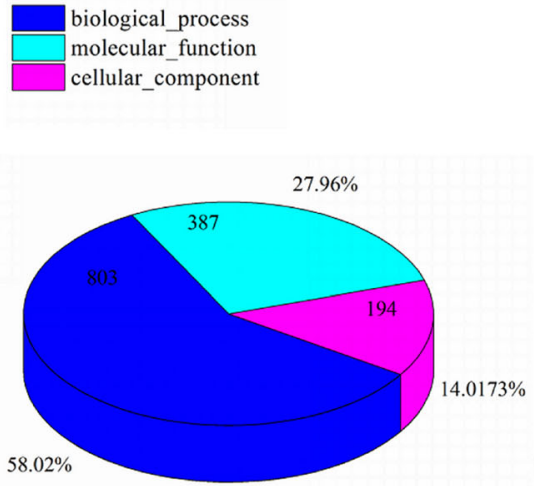

LPS vs PBS

B

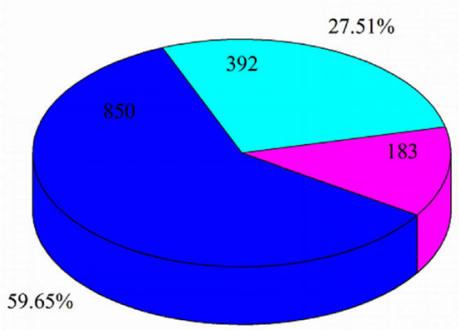

PGN vs PBS

C

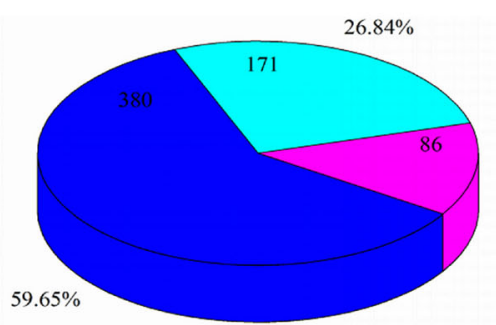

polyI_C vs PBS
D

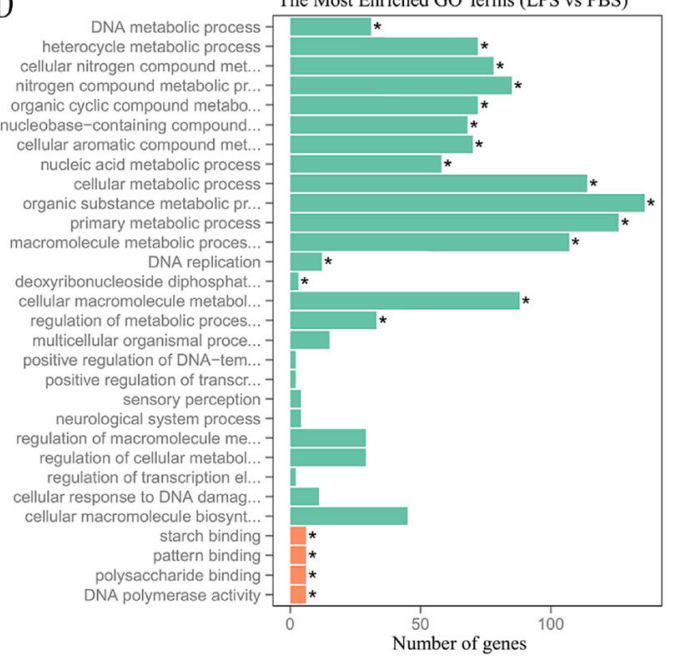

E cell cycle -
primary metabolic process-
macromolecule metabolic proces...-
monocarboxylic acid transport -
organic substance metabolic pr...-
positive regulation of autopha...
hucleobase-containing compound...-
heterocycle metabolic process starch binding-

ibonucleotide binding

purine nucleotide binding

ribonucleoside triphosp...

purine nucleoside binding

purine nibonucleoside binding

ribonucleoside binding

ribonucleoside binding

nucleoside binding

pattern bindingpattern binding -
polysaccharide binding-
GTP binding -

nucleotide binding

nucleotide binding

ucleoside phosphate binding

guanyl nucleotide binding
small molecule binding

anion binding

3,5-cyclic-nucleotide phosphod.

transferase activity, transf

The Most Enriched GO Terms (PBS vs PGN)

F
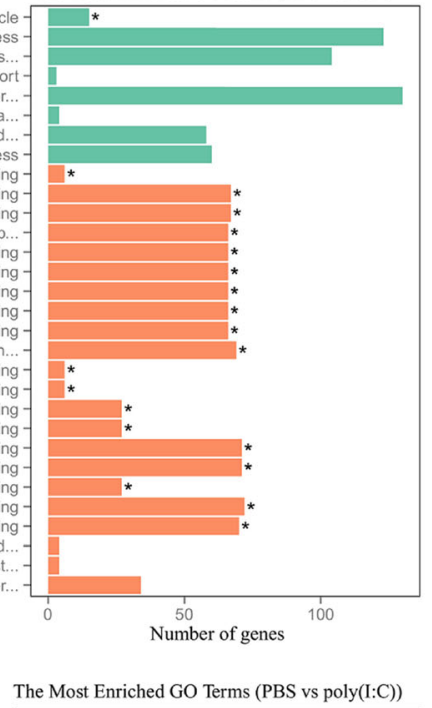

cellular component organizatio

cellular component organization.
defense respons

regulation of cell death

regulation of apoptotic process

regulation of programmed cell $d .$. .

translational initiation

GTP binding

guanyl nucleotide binding purine ribonucleoside triphosp.

purine nucleoside binding

purine nucleoside binding

purine ribonucleotide binding

ribonucleoside binding

bonucleotide binding

nucleoside binding

nucleotide binding

nucleotide binding

small molecule binding

anion binding

GTPase activity

heterocyclic compound binding organic cyclic compound binding hydrolase activity, acting on a. iglyceride lipase activity -triphosphatase activ pyrophosphatase activity biological_process

molecular_function

biological_proces

molecular_function

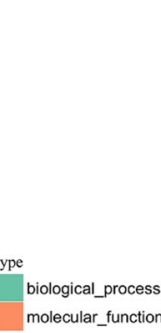

biological_process molecular_function

Fig. 4 (See legend on next page.) 
(See figure on previous page.)

Fig. 4 The proportion of biological process, molecular function, cell component $(\mathbf{a}, \mathbf{b}$, and $\mathbf{c})$ and the distribution of enriched GO terms (d, e, and f) in the hepatopancreas transcriptome of $R$. philippinarum post LPS, PGN, poly(l:C) injection. The most enriched GO terms shared by those groups were primarily involved in immune response (GO:0006955), response to host immune response (GO:0052572), pattern binding (GO:0001871), positive regulation of GTPase activity (GO:0043547), and regulation of cell death (GO:0010941)

by recognizing specific structures that are exposed to pathogens [22].

Lysozymes is a kind of alkaline enzyme that lyse bacteria by hydrolyzing the $\mathrm{b}-(1,4)$ linkage between $\mathrm{N}$-acetylmuramic acid and $\mathrm{N}$-acetylglucosamine of the peptidoglycan in bacterial cell walls [33]. The role of lysosomes in inflammatory response has been reported in Molluscan species [33, 34]. In bivalves, lysosomes were found within the granular hemocytes [35], and were released during degranulation of the granular haemocytes accompanies with phagocytosis [36]. The released enzymes then assist in the breakdown of foreign material [34]. It has been reported that a sub-lethal doses of the Listonella anguillarum (Gram-negative bacterium) tended to cause the destabilisation of the lysosomal membranes in Ostrea edulis, C. gigas, and Pecten maximus for a period of up to $48 \mathrm{~h}$ post-inoculation [35]. In the present study, the Lysosome pathway was conspicuously enriched between the LPS challenge group and the PBS control group (Fig. 5). In addition, five genes participating in the Lysosome pathways were significantly regulated in response to LPS challenge, indicating the Lysosome pathway plays a vital role in Gram-negative bacterium infection in $R$. philippinarum.

Table 2 The shared pathways enriched by DEGs among all 3 comparison groups (LPS vs PBS, PGN vs PBS and poly(l:C) vs PBS)

\begin{tabular}{|c|c|c|c|}
\hline Pathway ID & Pathway & $\boldsymbol{P}$ value & Class \\
\hline \multicolumn{4}{|c|}{ Shared by LPS, PGN, and poly(l:C) group } \\
\hline map 04611 & Platelet activation & 0.032959505 & Organismal Systems; Immune system \\
\hline map 04510 & Focal adhesion & 0.000108165 & Cellular Processes \\
\hline \multicolumn{4}{|c|}{ Shared by LPS and PGN group } \\
\hline map 03030 & DNA replication & 1.47E-10 & Genetic Information Processing; Replication and repair \\
\hline map 04110 & Cell cycle & 2.54E-09 & Cellular Processes; Cell growth and death \\
\hline map 04113 & Meiosis - yeast & 1.67E-08 & NO ENTRY FOUND. \\
\hline map 04115 & p53 signaling pathway & 8.51E-07 & Cellular Processes; Cell growth and death \\
\hline map 03460 & Fanconi anemia pathway & $5.38 \mathrm{E}-06$ & Genetic Information Processing; Replication and repair \\
\hline map 04971 & Gastric acid secretion & 8.67E-05 & Organismal Systems; Digestive system \\
\hline map 04921 & Oxytocin signaling pathway & 0.000627827 & Organismal Systems; Endocrine system \\
\hline map 04022 & cGMP-PKG signaling pathway & 0.000631031 & Environmental Information Processing; Signal transduction \\
\hline map 04270 & Vascular smooth muscle contraction & 0.002126258 & Organismal Systems; Circulatory system \\
\hline map 03410 & Base excision repair & 0.02148101 & Genetic Information Processing; Replication and repair \\
\hline map 04020 & Calcium signaling pathway & 0.032327041 & Environmental Information Processing; Signal transduction \\
\hline map 05166 & HTLV-I infection & 0.043004689 & NO ENTRY FOUND. \\
\hline map 00230 & Purine metabolism & 0.049496555 & Metabolism; Nucleotide metabolism \\
\hline \multicolumn{4}{|c|}{ Shared by LPS and poly(l:C) group } \\
\hline map 04145 & Phagosome & 0.014509814 & Cellular Processes; Transport and catabolism \\
\hline \multicolumn{4}{|c|}{ Shared by PGN and poly(l:C) group } \\
\hline map 05133 & Pertussis & 5.32E-05 & Human Diseases; Infectious disease: bacterial \\
\hline map 04974 & Protein digestion and absorption & 0.003941603 & Organismal Systems; Digestive system \\
\hline map 04512 & ECM-receptor interaction & 0.001614027 & Environmental Information Processing; Signaling molecules and interaction \\
\hline map 04610 & Complement and coagulation cascades & 0.000712509 & Organismal Systems; Immune system \\
\hline map 05130 & Pathogenic Escherichia coli infection & 0.013636368 & Human Diseases; Infectious disease: bacterial \\
\hline map 05322 & Systemic lupus erythematosus & 0.011539281 & Human Diseases; Immune disease \\
\hline
\end{tabular}




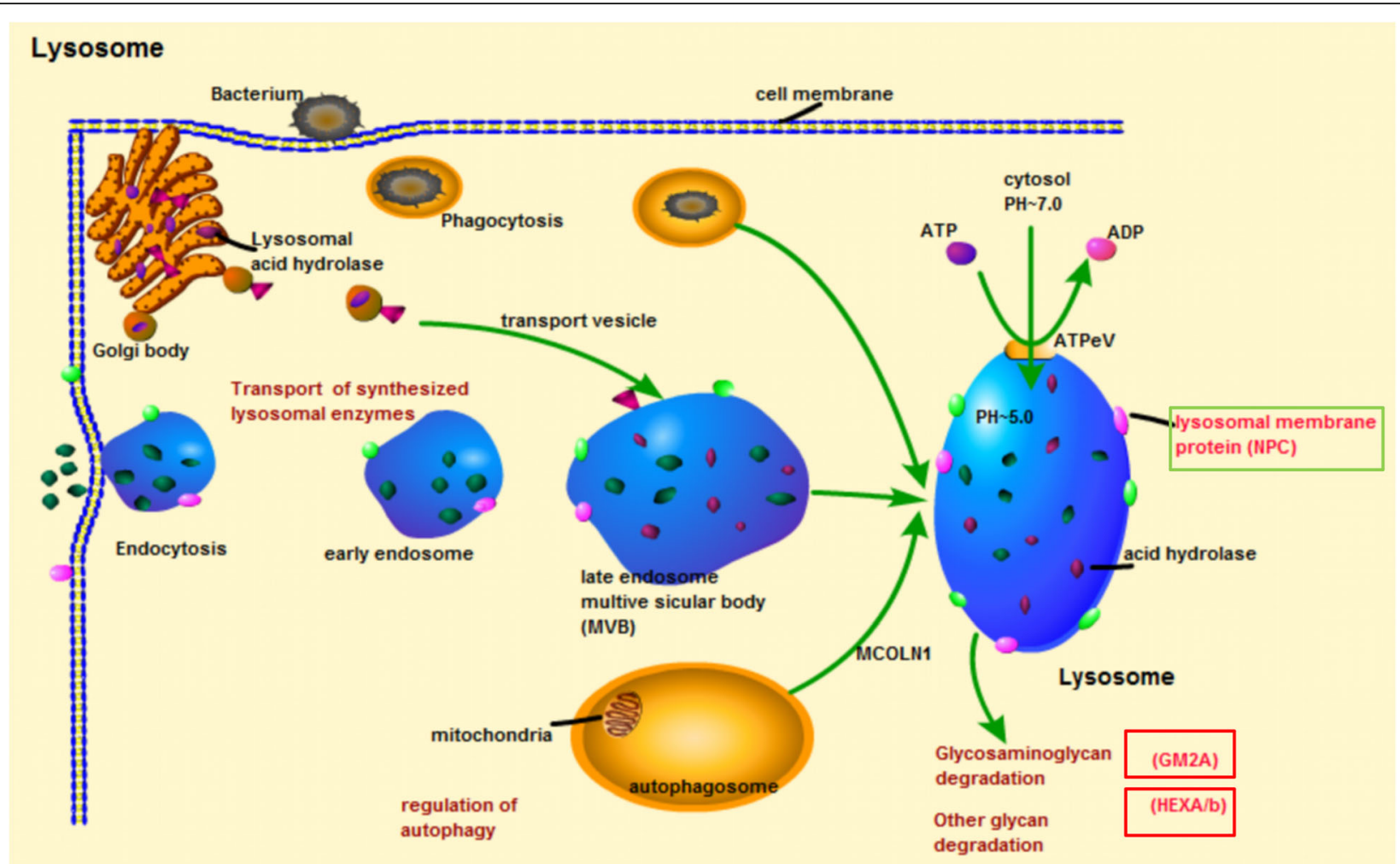

Fig. 5 The Lysosome signaling pathway and DEGs in Lysosome pathway from KEGG enrichment analysis of R. philippinarum in LPS challenge group. The red colored genes were the DEGs in Lysosome pathway

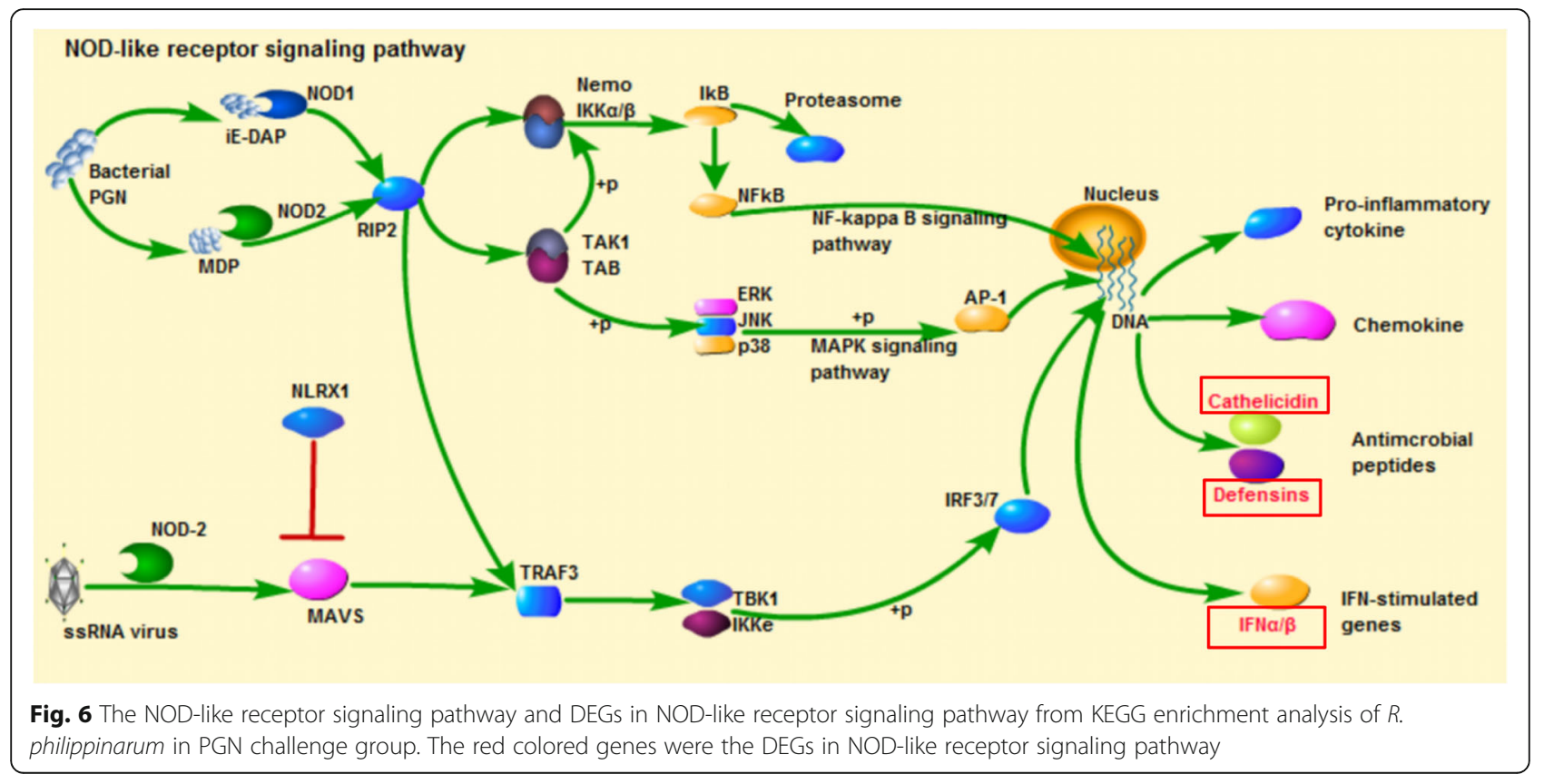



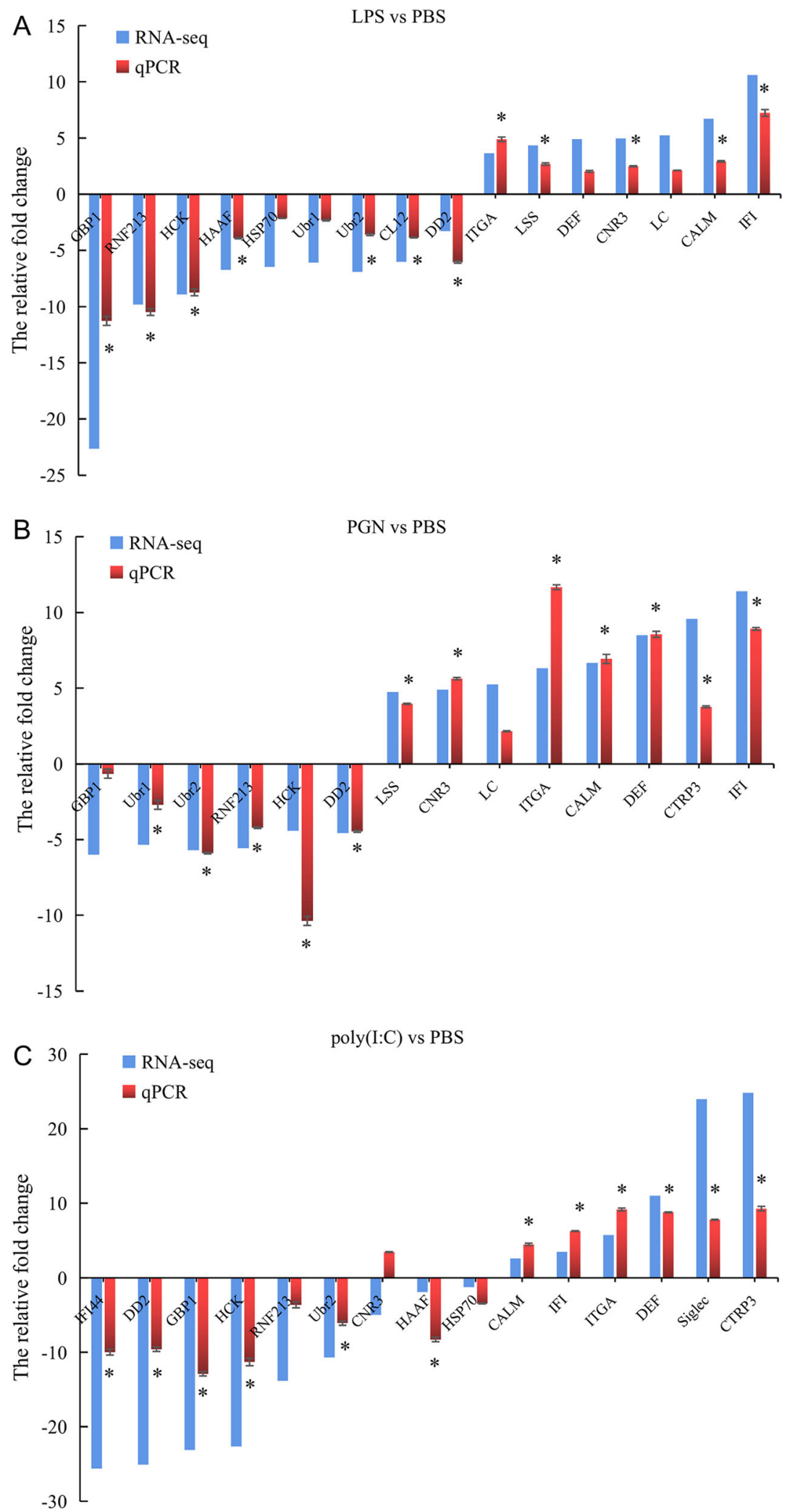

Fig. 7 Validation of RNA-Seq results using qRT-PCR. The transcript expression levels of the selected genes were normalized to that of the $\beta$-actin gene 
Intracellular PRMs, such as NOD-like receptor, could recognize virus-derived dsRNA and bacteria-derived peptidoglycan, and induce the inflammatory response [36]. More than 20 NOD-like receptors that play a key role in the recognition of intracellular ligands have been found in mammals [36]. Recently, it has been reported that Nod1 and Nod2 identify different sites of bacterial PGN and mediate innate immunity [37]. In Manila clam, the previous study reported that NOD-like receptor signaling pathway was enriched in the hepatopancreas transcriptome of $R$. philippinarum after challenged by Vibrio anguillarum [18]. In the current work, a total of 16 DEGs, such as caspase, CATH, DEFs, interferon-induced proteins $(I F I)$, and Interferon-induced guanylate-binding proteins $(G B P)$ in NOD-like receptor signaling pathway were highly regulated in response to PGN challenge in $R$. philippinarum (Fig. 6). Our finding indicated that NOD-like receptor signaling pathway might plays an important role in response to the Gram-positive bacterium in $R$. philippinarum.

Based upon the number of DEGs and pathways (Fig. 3a), $R$. philippinarum exhibited a stronger immune response to LPS and PGN challenge than to poly(I:C) challenge [38]. Interestingly, we found the transcriptomic responses of $R$. philippinarum to LPS and PGN shared more DEGs, including C1qL, CTL, $S R C R, C A T H$, coagulation factor $\mathrm{X}$ (FA10), Leucinerich repeat-containing protein $(L R 74 A)$, etc. This result might be due to both LPS and PGN are derived from bacteria (Gram-negative and Gram-positive, respectively), whereas poly(I:C) is a synthetic analog of dsRNA associated with viral infection [29].

Some PAMPs, such as LPS and PGN, could activate TLRs and trigger the release of pro-inflammatory cytokines to induce immune response [39]. The present study demonstrates that PAMPs could significantly change the transcription level of immune-related genes involved in pathogen recognition (e.g. FREP, C1qL, FCN, TLR, PGRP, Perlucin, MMR1, CTL, CL, SRCR, LTL, Siglec) and killing (C3, DEF, CATH, FCGBP, FCGR), apoptosis regulation (DAPK, CNR, caspase), and stress response (HSP70). FREP, C1qL, FCN, TLR, PGRP, Perlucin, $M M R 1$, SRCR, and Lectins (CTL, CL, Siglec, LTL) all belong to PRRs $[12,25]$, serve as dedicated sensors and/ or exclusive effectors [40], and play a prominent role in activating intracellular signaling pathways and triggering the synthesis of antimicrobial effectors [41].

Among those PRRs, C1qL is described remarkably expanded in $R$. philippinarum [42]. It has been reported that some $\mathrm{C1qL}$ proteins are the first PRMs of the complement system from the evolutionary perspective [43]. Complement $\mathrm{C} 1 \mathrm{q}$-like proteins contain the $\mathrm{C} 1 \mathrm{q}$ domain and were grouped as the C1qDC [43]. A total of 168 different transcripts of $\mathrm{C} 1 \mathrm{qDC}$ was found in Mytilus galloprovincialis, most of which show differential expression following challenge with Gram-positive or -negative bacteria $[44,45]$, and the same expression pattern was also found in Mytilus edulis [46]. In this study, three C1qL genes were detected, and two C1qL genes showed up-regulated expression, while the other $C 1 q L$ showed down-regulation. A similar result was found in $R$. philippinarum in response to brown ring disease [6] and other Molluscs [17, 45]. Therefore, It is conceivable that some $C 1 q L$ transcripts are up-regulated while the others are down-regulated providing a tailored response to pathogens in $R$. philippinarum [6]. In addition, C3, CTRP, $F C G R$, and FCGBP also were detected highly regulated in PAMPs treatment groups. C3 functions as the key molecular of complement system to distinguish and eliminate pathogens, and induce inflammatory responses [47]. The membrane-attached CTRP is the initial prototype of $\mathrm{C} 1 \mathrm{q}$ and acting as immune PRM activating the proto-complement $[43,44]$. Besides, $F C N$, a derivative of the lectin pathway of complement activation [43], was found significantly up-regulated under LPS challenge in our study. To sum up, a rudimentary complement system with a group of expanded and diversified genes is suggested to exist in $R$. philippinarum and play a crucial role in the innate defense against pathogens [43].

PGRPS is considered to be a crucial immune molecule in Molluscs by detecting and eliminating invading bacteria [48-52]. The expression pattern of PGRP has been investigated in Chlamys farreri [49], Solen grandis [51], and Hyriopsis cumingi [52]. In this study, the upregulated expression of PGRPs was not only detected in PGN challenged clams but also in LPS and poly(I:C) challenged clams (Table. 1). Similar results were found in C. farreri and S. grandis $[49,51]$. In C. farreri, the CfPGRP-S1 was a constitutive and inducible acute-phase protein that was involved in the immune response against both the Gram-positive bacteria and Gramnegative bacteria infection [49]. The expression of SgPGRP-S2 was significantly up-regulated when $S$. grandis was stimulated by LPS, PGN, and b-1,3-glucan [51]. In Pacific oyster, a CgPGRP-S1S gene was found greatly contribute to efficient host defense systems, not only by direct interaction with bacteria, but also by triggering other defense pathways [50]. Therefore, we speculate PGRPs might not only serve as PRRs to recognize Gram-positive bacteria, but also participate in other defense pathways to respond to different pathogens invasion in $R$. philippinarum.

Immune effectors are usually induced by PRRs recognition and produced by epithelial cells from various organs, including AMPs, lysozymes, cytokines, antioxidant enzymes, and acute phase proteins [19]. In this study, two kind of AMPs $(D E F, C A T H)$ were annotated in DEGs in response to PAMPs. DEF is a large group of 
small antimicrobial peptides and involved in the host immune response against bacterial infection [53-57]. Various $D E F$ s have been characterized in different bivalve species such as Venerupis philippinarum [53], $C$. gigas [54], Argopecten irradians [56], and R. philippinarum $[55,57]$. In C. gigas, Cg-def gene exhibits high activities against Gram-positive bacteria but low activity against Gram-negative bacteria and fungi [54]. It has been reported Rpdef showed the highest activity against Gram-positive bacteria and played an important role in the elimination of invading bacterium through membrane-disruptive activity in $R$. philippinarum [55, 57]. In this study, two DEF (defensin and defensin-B) with six conserved cysteines were identified, which is consistent with previous reports of arthropod-like defensins in other Molluscs $[54,56,58]$. Both of the two DEF exhibited highly increasing expression in response to LPS and PGN challenge, especially the defensin gene increased 26.8- and 26.3-fold, respectively. The defensin- $B$ showed a significantly up-regulated expression level in response to LPS, PGN, and poly(I:C). Our result indicates $D E F$ s play vital roles in response to Gram-positive and -negative bacteria and virus invasion in $R$. philippinarum. Cathelicidins (CATHs) have broad antimicrobial activity against Gram-positive and Gram-negative bacteria in the insect [59]. However, little is known of the $C A T H \mathrm{~s}$ in bivalves, especially in $R$. philippinarum. In this study, the expression level of Cathelicidin-B1 in $R$. philippinarum after LPS and PGN challenge was upregulated (4.65- and 4.09-fold, respectively). We speculated that $C A T H$ is an essential molecule in $R$. philippinarum immunity system and may be utilized as executors for the incapacitation and elimination of Gram-positive and Gram-negative bacteria invasion.

Peroxidase-like protein $(P O)$ belongs to the antioxidant enzymes [60]. Some reactive oxygen species (ROS) are highly harmful and toxic to organism and are significantly induced when attacked by invaders or stress [61, 62]. Organisms have formed an antioxidant defense system that removes ROS to protect cells from damage caused by abundant ROS [12]. In the present study, the $P O$ gene was found significantly down-regulated ( -4.32 fold change) in the LPS group, indicating the efficiency of ROS removing was decreased and the immune system was affected in $R$. philippinarum after LPS challenge. Heat shock proteins (HSPs) are evolutionarily ancient and highly conserved intracellular molecular chaperones [19]. The primary role of HSP is to function as molecular chaperones to modulate stress response [12]. When organisms are stressed by environmental conditions, the expression level of HSP would significantly increase, enabling the organism could resist the damage caused by adverse environment to maintain homeostasis and cell survival [63, 64]. In this study, $H S P$ s with up-regulated expression were found both in
LPS, PGN, and poly $(\mathrm{I}: \mathrm{C})$ challenge group, indicating the activity of HSPs is closely linked to the innate immune system in R. philippinarum [65].

Another group of transcripts highly regulated in PAMPs challenged clams were interferon-induced proteins (IFI) and Interferon-induced guanylate-binding proteins $(G B P)$. It has been reported that viral infection could trigger the interferon and interferon-induced genes highly upregulated in salmonids and rainbow trout $[66,67]$. In bivalves, $C g I F N L P$ was found to increase significantly at $12 \mathrm{~h}$ (8.35-fold) and $24 \mathrm{~h}$ (4.95-fold) after poly(I:C) stimulation in C. gigas hemocytes [30]. GBP countered the antiviral effect by inhibition of its GTPase activity in Mammalian [68]. In this study, the expression of 5 IFI and 3 GBP genes was found highly regulated by poly(I:C) in $R$. philippinarum (IFI 3.46, 11.07, 5.10, -5.44, - 25.60, fold, and GBP $-24.42,-23.09,-9.27$ fold, respectively), while only 2 of IFI and 2 of GBP genes were regulated by LPS and PGN, and the expression level of those genes was similar. It is therefore plausible that some IFI were up-regulated, whereas others are switched down providing a tailored response to pathogens infection in R. philippinarum. Overall, these findings indicating IFI and GBP might play a crucial role in response to viral invasion in $R$. philippinarum.

\section{Conclusions}

The transcriptome comparison of the different PAMPs challenged Manila clam has provided new useful data to understand the molecular basis of the immune response to pathogens. The genome-based transcriptome analysis revealed LPS and PGN are more potent PAMPs in activating the immune response in $R$. philippinarum. LPS challenge group shared more immune-related DEGs and immune response pathways with PGN challenge group than poly(I:C) stimulation. Besides, some significantly enriched specific pathways directly related to immune response were found, such as the Lysosome pathway in the LPS challenge group, NOD-like receptor signaling pathway in the PGN challenge group. Moreover, some PRRs (FREP, C1qL, FCN, TLR, PGRP, Perlucin, MMR1, CTL, $C L, S R C R, L T L$, Siglec), AMPs (DEFs, CATH), interferoninduced proteins (IFI, GBP), HSPs, and $P O$ were identified, which play pivotal roles in identification and clearance of invading pathogens in $R$. philippinarum. Our finding will aid understanding of $R$. philippinarum immune system and defense response to different pathogens invasion and provide new insights to develop effective control strategies for different pathogens.

\section{Methods}

Manila clam and PAMPs challenge

The wild adult Manila clams used in this study were collected from Jinshitan, Dalian, Liaoning Province, China. 
The clams had an average shell length of $23.2 \pm 1.0 \mathrm{~mm}$, and an average weight of $5.4 \pm 0.8 \mathrm{~g}$. After being transported to the laboratory, the clams were cleaned to remove any fouling and were acclimated in aerated $20 \mathrm{~L}$ plastic tanks, containing water at $13.8 \pm 0.6^{\circ} \mathrm{C}, \mathrm{pH} 8.1 \pm$ 0.1 with a salinity of $30 \mathrm{ppt}$. The clams were fed with Spirulina powder once a day for 2 weeks and the water was exchanged fully once per day to discharge waste products. Clams in each group were fasted at least 2 days before injection to avoid food contamination.

Three PAMPs were used in this study, including LPS from the bacterium Escherichia coli 055:B5 (Solarbio, Beijing, China), PGN from Staphylococcus aureus (InvivoGen, USA), and synthetic dsRNA poly(I:C) (InvivoGen, USA). All three PAMPs were dissolved in $1 \times$ PBS (phosphate-buffered saline, Solarbio, Beijing, China) at a concentration of $100 \mu \mathrm{g} / \mathrm{mL}$ (LPS and PGN) and $20 \mathrm{mg} /$ $\mathrm{mL}$ (PGN) according to a previous study [69]. Clams were divided into three PAMP challenge groups including LPS group (LPS1, LPS2, LPS3), PGN group (PGN1, PGN2, PGN3), poly(I:C) group (poly(I:C)_1, poly(I:C)_2, poly(I:C)_3), and PBS control group (PBS1, PBS2, PBS3), respectively (each group $n=20$ ). The clams from three PAMPs groups and PBS control group were injected into the sinusoid with approximately $50 \mu \mathrm{L}$ of LPS $(100 \mu \mathrm{g} / \mathrm{mL}), 50 \mu \mathrm{L}$ of PGN $(20 \mu \mathrm{g} / \mathrm{mL}), 50 \mu \mathrm{L}$ of poly(I: C) $(100 \mu \mathrm{g} / \mathrm{mL})$, and $50 \mu \mathrm{L} 1 \times$ PBS, respectively. At $24 \mathrm{~h}$ post-injection, three clams in each group were randomly selected and the hepatopancreas was collected and immediately frozen in liquid nitrogen and stored at $-80^{\circ} \mathrm{C}$ prior to use.

\section{RNA extraction and library construction for Illumina sequencing}

Total RNA was extracted from $30 \mathrm{mg}$ hepatopancreas of each individual (each group $n=3$ ) using RNAprep pure Tissue Kit (TianGene, Beijing, China), according to the manufacturer's protocol. The degradation and contamination of total RNA were monitored on 1\% agarose gels. RNA purity and concentration were measured using the NanoPhotometer ${ }^{\circ}$ spectrophotometer (IMPLEN, CA, USA) and Qubit $^{\circ}$ RNA Assay Kit in Qubit $^{\circ} 2.0$ Fluorometer (Life Technologies, CA, USA), respectively.

A total amount of $3 \mu \mathrm{g}$ RNA per sample was used as input material for the RNA sample preparations. Sequencing libraries were generated using $\mathrm{NEBNext}^{\circ}$ UltraTM RNA Library Prep Kit for Illumina ${ }^{\circ}$ (NEB, USA) following the manufacturer's recommendations and index codes were added to attribute sequences to each sample [70]. Fragmentation was carried out using divalent cations under elevated temperature in NEBNext First-strand Synthesis Reaction Buffer (5X) [70, 71]. The first-strand cDNA was synthesized using random hexamer primer and M-MuLV Reverse Transcriptase
(RNase H) [71]. Second strand cDNA synthesis was subsequently performed using DNA Polymerase I and RNase H. After adenylation of 3' ends of DNA fragments, NEBNext Adaptor with hairpin loop structure was ligated to prepare for hybridization [71]. To select cDNA fragments of preferentially $250 \sim 300 \mathrm{bp}$ in length, the library fragments were purified with AMPure XP system (Beckman Coulter, Beverly, USA) [72]. Then $3 \mu \mathrm{L}$ USER enzyme (NEB, USA) was used with sizeselected, adaptor-ligated $\mathrm{cDNA}$ at $37^{\circ} \mathrm{C}$ for $15 \mathrm{~min}$ followed by $5 \mathrm{~min}$ at $95^{\circ} \mathrm{C}$ before PCR. PCR was performed with Phusion High-Fidelity DNA polymerase, Universal PCR primers, and Index (X) Primer [72]. At last, PCR products were purified (AMPure XP system) and library quality was assessed on the Agilent Bioanalyzer 2100 system [72].

\section{Sequence filtering, mapping, and assembly}

Raw reads of fastq format were firstly processed through in-house Perl scripts [73]. In this step, clean reads were obtained by removing reads containing adapter, reads containing ploy- $\mathrm{N}$ and low quality reads from raw data [73]. Clean reads were mapped to the reference genome of the R. philippinarum published in our previous study (https:// www.ncbi.nlm.nih.gov/genome/?term=txid129788[orgn]) [21]. Index of the reference genome was built using Hisat2 v2.0.5 and paired-end clean reads were aligned to the reference genome using Hisat2 v2.0.5 [73]. We selected Hisat2 as the mapping tool for that Hisat2 can generate a database of splice junctions based on the gene model annotation file and thus a better mapping result than other non-splice mapping tools [74, 75]. Feature Counts v1.5.0-p3 was used to count the reads numbers mapped to each gene, and then FPKM of each gene was calculated based on the length of the gene and reads count mapped to this gene [76]. The $P$ values were adjusted using the Benjamini \& Hochberg method [77]. Next, the alignments are passed to StringTie (http://www.ccb. jhu.edu/ software/stringtie/) for transcript assembly. StringTie assembles the genes for each data set separately, estimating the expression levels of each gene and each isoform as it assembles them [78].

\section{Differential expression analysis}

Differential expression analysis of two groups was performed using the DESeq2 R package [74]. DESeq2 provides statistical routines for determining differential expression in digital gene expression data using a model based on the negative binomial distribution [74]. The resulting $P$-values were adjusted using the Benjamini and Hochberg's approach for controlling the false discovery rate [79]. Genes with an adjusted $P$-value $<0.05$ found by DESeq2 were assigned as differentially expressed. 


\section{GO and KEGG enrichment analysis of differentially expressed genes}

Using transcripts from the reference genome [21], we annotated gene functions using the Gene Ontology (GO), and Kyoto Encyclopedia of Genes and Genomes (KEGG) database. GO enrichment analysis of differentially expressed genes (DEGs) was implemented by the cluster Profiler R package, in which gene length bias was corrected [80]. GO terms with corrected $P$-value less than 0.05 were considered significantly enriched by differential expressed genes [74]. KEGG is a database resource for understanding high-level functions and utilities of the biological system, such as the cell, the organism and the ecosystem, from molecular-level information, especially large-scale molecular data sets generated by genome sequencing and other highthroughput experimental technologies (http://www.genome.jp/kegg/) [74]. We used the cluster Profiler R package to test the statistical enrichment of differential expression genes in KEGG pathways [70].

\section{qPCR confirmation of Illumina sequencing data}

To validate the Illumina sequencing data, twenty immune-related DEGs were chosen for quantitative realtime PCR (qPCR) analysis. The integrity and purity of RNA were determined by electrophoresis on a $1 \%$ agarose gel and a Nanodrop ND-2000 spectrophotometer (Thermo Electron Corp., Waltham, MA, USA), respectively. Total RNA was reverse-transcribed to cDNA with the PrimeScript RT reagent Kit (TaKaRa, Tokyo, Japan). The primers were designed with the Primer 5 software (Premier Biosoft International). The $\beta$-actin was selected as a reference gene for the qPCR analysis, due to its stably expressed characteristic $[25,26]$. The qPCR was performed with TB Green Premix ExTaqII (TaKaRa, Tokyo, Japan). The reactions were carried out in a total volume of $20 \mu \mathrm{L}$ containing $2 \mu \mathrm{L}$ of diluted cDNA $(50 \mu \mathrm{g} / \mu \mathrm{L})$, $1 \mu \mathrm{L}$ of each primer, $10 \mu \mathrm{L}$ of TB Green PCR Master Mix and $6 \mu \mathrm{L}$ of $\mathrm{H}_{2} \mathrm{O}$, with the following cycling profile: $94{ }^{\circ} \mathrm{C}$ for $5 \mathrm{~min}, 40$ cycles of $94^{\circ} \mathrm{C}$ for $30 \mathrm{~s}, 60^{\circ} \mathrm{C}$ for $30 \mathrm{~s}$, and $72^{\circ} \mathrm{C}$ for $30 \mathrm{~s}$. Each sample was processed in triplicate in the Roche LightCycler 480 Real-Time PCR System (Roche Diagnostics Burgess Hill, UK). The $2^{-\Delta \Delta C T}$ method [81] was used to analyze the expression level.

\section{Supplementary information}

Supplementary information accompanies this paper at https://doi.org/10. 1186/s12864-020-06914-2.

Additional file 1. Summary statistics of $R$. philippinarum transcriptome assembly. Q20, Q30: the percentage of bases with a Phred value of > 20 or 30 .

Additional file 2. The density distribution of expression level of mapped clean read in LPS, PGN, poly (l:C), and PBS group.
Additional file 3. Kyoto Encyclopedia of Genes and Genomes (KEGG) assignment of unigenes in the transcriptome of $R$. philippinarum after LPS, PGN, poly(l:C) injection.

Additional file 4. Primers used for $\mathrm{QPCR}$ in this study.

\section{Abbreviations}

PAMPs: Pathogen-associated molecular patterns; LPS: Lipopolysaccharide; PGN: Peptidoglycan; poly(l:C): Polyinosinic-polycytidylic acid; PBS: Phosphate buffered saline; RNA-seq: RNA sequencing technology; DEGs: Differentially expressed genes; PRRs: Pattern recognition receptors; AMPs: Antimicrobial peptides; GO: Gene ontology; KEGG: Kyoto encyclopedia of genes and genomes; IFI: Interferon-induced proteins; PRMs: Pattern recognition molecules; DEF: Defensin; MUCL: Mucin-like protein; RNF213: E3 ubiquitinprotein ligase; CELSR: Cadherin EGF LAG seven-pass G-type receptor; CTRP: Complement C1q tumor necrosis factor-related protein;

PGRP: Peptidoglycan recognition protein; TLR: Toll-like receptor; FCN: Ficolin; CL: Collectin; C1qL: Complement c1q-like protein; C3: Complement component C3; CALM: Calmodulin; CRIP2: Cysteine-rich protein; FREP: Fbrinogen-like protein; SPI: Serine protease inhibitor; IFI: Interferon alpha-inducible protein; HSP70: Heat shock 70 kDa protein; SRCR: Scavenger receptor cysteine-rich; FCGBP: IgGFc-binding protein; FCGR: Low affinity immunoglobulin epsilon Fc receptor; CNR: Cell number regulator 3;

TGFBI: Transforming growth factor-beta-induced protein; ADGRE1: Adhesion G protein-coupled receptor; LTL: L-Type lectin; MMR1: Macrophage mannose receptor 1; DD2: Discoidin-2; DAPK: Death-associated protein kinase; Siglec: Sialic acid-binding lectin; NLR: NOD-like receptor; CTL: C-type lectin; FA10: Coagulation factor X; LR74A: Leucine-rich repeat-containing protein; PO: Peroxidase-like protein; ROS: Reactive oxygen species; HSPs: Heat shock proteins

\section{Acknowledgements}

We would like to give thanks to Mr. Jie Liu and Mr. Ning Li for their help to prepare the experiment.

\section{Authors' contributions}

$\mathrm{K}, \mathrm{HN}$ conducted preparation of the transcriptome data, bioinformatics analysis and manuscript preparation. $\mathrm{KJ}$ and $\mathrm{DL}$ were involved in one or more processes of sample collection, RNA extraction or experimental and data analysis. HTN and XWY conceived, designed and guided the research. All authors read and approved the final manuscript.

\section{Funding}

This work was supported by the National Key R\&D Program of China (2018YFD0901400), the Modern Agro-industry Technology Research System (CARS-49), the Outstanding Chinese and Foreign Youth Exchange Program of China Association of Science and Technology, and Liaoning BaiQianWan talent program. The funders had no role in study design, data collection and analysis, decision to publish, or preparation of the manuscript.

\section{Availability of data and materials}

The transcriptome sequencing clean data have been submission to the SRA database in NCBI (https://www.ncbi.nlm.nih.gov/sra/?term=PRJNA616201) with accession number (PRJNA616201).

\section{Ethics approval and consent to participate} Not Applicable.

\section{Consent for publication}

Not Applicable.

\section{Competing interests}

The authors declare that they have no competing interests.

Received: 12 March 2020 Accepted: 14 July 2020

Published online: 01 August 2020

References

1. FAO. Fishery and Aquaculture Statistics. 2019; http://www.fao.org/fishery/ static/Yearbook/YB2017_USBcard/booklet/CA5495T_web.pdf. 
2. Zhang GF, Yan XW. Clam aquaculture. Beijing, China (in Chinese: Science Press; 2010.

3. Allam B, Paillard C, Ford SE. Pathogenicity of Vibrio tapetis, the etiological agent of brown ring disease in clams. Dis Aquat Org. 2002;48:221-31. https://doi.org/10.3354/dao048221.

4. Moreira R, Balseiro P, Romero A, Dios S, Posada D, Novoa B, et al. Gene expression analysis of clams Ruditapes philippinarum and Ruditapes decussatus following bacterial infection yields molecular insights into pathogen resistance and immunity. Dev Comp Immunol. 2012;36:140-9. https://doi.org/10.1016/j.dci.2011.06.012.

5. Moreira R, Milan M, Balseiro P, Romero A, Babbucci M, Figueras A, et al. Gene expression profile analysis of manila clam (Ruditapes philippinarum) hemocytes after a Vibrio alginolyticus challenge using an immune-enriched oligo microarray. BMC Genomics. 2014;15:267-82. https:/doi.org/10.1186/ 1471-2164-15-267.

6. Allam B, Espinosa EP, Jeffroy F, Tanguy A, Paillard C. Transcriptional changes in manila clam (Ruditapes philippinarum) in response to brown ring disease. Fish Shellfish Immunol. 2014;41:2-11. https://doi.org/10.1016/j.fsi.2014.05.022.

7. Gestal C, Roch P, Renault T, Pallavicini A, Paillard C, Novoa B, et al. Study of diseases and the immune system of bivalves using molecular biology and genomics. Rev Fish Sci. 2008;16:131-54. https://doi.org/10.1080/ 10641260802325518

8. Moreira R, Milan M, Balseiro P, Romero A, Babbucci M, Figueras A, et al. Gene expression profile analysis of Manila clam (Ruditapes philippinarum) hemocytes after a Vibrio alginolyticus challenge using an immune-enriched oligo-microarray. Fish Shellfish Immunol. 2013;34:1666-7. https://doi.org/10. 1186/1471-2164-15-267.

9. Waki T, Shimokawa J, Watanabe S, Yoshinaga T, Ogawa K. Experimental challenges of wild Manila clams with Perkinsus species isolated from naturally infected wild Manila clams. J Invertebr Pathol. 2012;111:50-5. https://doi.org/10.1016/j.jp.2012.05.009.

10. Hasanuzzaman AFM, Robledo D, Gómez-Tato A, Alvarez Dios JA, Harrison PW, Cao A, et al. Transcriptomic profile of Manila clam (Ruditapes philippinarum) haemocytes in response to Perkinsus olseni infection. Aquaculture. 2017;467: 170-81. https://doi.org/10.1016/j.aquaculture.2016.06.007.

11. Moreira R, Balseiro P, Planas JV, Fuste B, Beltran S, Novoa B, et al. Transcriptomics of in vitro immune-stimulated Hemocytes from the Manila clam Ruditapes philippinarum using high-throughput sequencing. PLoS One. 2012;7:e35009. https://doi.org/10.1371/journal.pone.0035009.

12. Wang L. X Song, L Song. The oyster immunity. Dev Comp Immunol. 2018; 80:99-118. https://doi.org/10.1016/j.dci.2017.05.025.

13. Jin W, Fan ZX. Progress in pattern recognition receptors of innate immunity in invertebrates. Prog Biochem Biophys. 2004;31:112-7.

14. Sun J, Wang L, Yang C, Song L. An ancient BCR-like signaling promotes ICP production and hemocyte phagocytosis in oyster. iScience. 2020;23(2): 100834. (doi.org/https://doi.org/10.1016/j.isci.2020.100834).

15. Moreira R, Pereiro P, Canchaya C, Posada D, Figueras A, Novoa B. RNA-Seq in Mytilus galloprovincialis: comparative transcriptomics and expression profiles among different tissues. BMC Genomics. 2015;16:728-46. https://doi. org/10.1186/s12864-015-1817-5.

16. Zhang G, Fang X, Guo X, Li L, Luo R, Xu F, et al. The oyster genome reveals stress adaptation and complexity of shell formation. Nature. 2012;490:49-54. https://doi.org/10.1038/nature11413.

17. Li Y, Sun X, Hu X, Xun X, Zhang J, Guo X, et al. Scallop genome reveals molecular adaptations to semi-sessile life and neurotoxins. Nat Commun. 2017;8:1721-31. https://doi.org/10.1038/s41467-017-01927-0.

18. Ren Y, Xue J, Yang H, Pan B, Bu W. Transcriptome analysis of, Ruditapes philippinarum, hepatopancreas provides insights into immune signaling pathways under, vibrio anguillarum, infection. Fish Shellfish Immunol. 2017; 64:14-23. https://doi.org/10.1016/j.ffi.2017.03.005

19. Yan $X$, Nie H, Huo Z, Ding J, Li Z, Yan L, et al. Clam genome sequence clarifies the molecular basis of its benthic adaptation and extraordinary shell color diversity. iScience. 2019;19:1225-37. https://doi.org/10.1016/j.isci.2019.08.049.

20. Nie $H$, Wang $H$, Jiang $K$, Yan X. Transcriptome analysis reveals differential immune related genes expression in Ruditapes philippinarum under hypoxia stress: potential HIF and NF-KB crosstalk in immune responses in clam. BMC Genomics. 2020;21:318. https://doi.org/10.1186/s12864-020-6734-6.

21. Nie H, Jiang K, Li N, Li D, Yan X. Transcriptomic analysis of Ruditapes philippinarum under aerial exposure and reimmersion reveals genes involved in stress response and recovery capacity of the Manila clam. Aquaculture. 2020; 524,735271. https://doi.org/10.1016/j.aquaculture.2020.735271.
22. Janeway CA Jr, Medzhitov R. Innate immune recognition. Annu Rev Immunol. 2002;20:197-216. https://doi.org/10.1146/annurev.immunol.20. 083001.084359 .

23. Sullivan JT, Belloir JA. Activation of an innate immune response in the schistosome-transmitting snail Biomphalaria glabrata by specific bacterial PAMPs. Dev Comp Immunol. 2014;42:256-66. https://doi.org/10.1016/j.dci. 2013.09.016.

24. Sullivan JT, Bulman CA, Salamat Z. Effect of crude lipopolysaccharide from Escherichia coli 0127:B8 on the amebocyte-producing organ of Biomphalaria glabrata (Mollusca). Dev Comp Immunol. 2011;35:1182-7. https://doi.org/10.1016/j.dci.2011.03.032.

25. Li D, Nie H, Dong S, Huo Z, Yan X. Molecular cloning and expression analysis of C-type lectin (RpCTL) in Manila clam Ruditapes philippinarum after lipopolysaccharide challenge. Fish Shellfish Immunol. 2019;86:981-93. https://doi.org/10.1016/j.fsi.2018.12.033.

26. Li D, Nie H, Jiang K, Li N, Huo Z, Yan X. Molecular characterization and expression analysis of fibrinogen related protein (FREP) genes of Manila clam (Ruditapes philippinarum) after lipopolysaccharides challenge. Comp Biochem Physiol. Part C Toxicol Pharmacol. 2020;228:108672-81. https://doi. org/10.1016/j.cbpc.2019.108672.

27. Zhang $Y, Y u Z$. The first evidence of positive selection in peptidoglycan recognition protein (PGRP) genes of Crassostrea gigas. Fish Shellfish Immunol. 2013;34:1352-5. https://doi.org/10.1016/j.fsi.2013.01.018.

28. Wang W, Zhang T, Wang L, Xu J, Li M, Zhang A, et al. A new nonphagocytic TLR6 with broad recognition ligands from Pacific oyster Crassostrea gigas. Dev Comp Immunol. 2016;65:182-90. https://doi.org/10. 1016/j.dci.2016.07.010

29. Misako M, Tsukasa S. TLR3: interferon induction by double-stranded RNA including poly(l:C). Adv Drug Deliv Rev. 2007;60:805-12. https://doi.org/10. 1016/j.addr.2007.11.005.

30. Zhang R, Liu R, Wang W, Xin L, Wang L, Li C, et al. Identification and functional analysis of a novel IFN-like protein (CgIFNLP) in Crassostrea gigas. Fish Shellfish Immunol. 2015;44:547-54. https://doi.org/10.1016/j.fsi.2015.03.015.

31. Li C, Qu T, Huang B, Ji P, Huang W, Que H, et al. Cloning and characterization of a novel caspase-8-like gene in Crassostrea gigas. Fish Shellfish Immunol. 2015;46:486. https://doi.org/10.1016/j.fsi.2015.06.035.

32. Mortazavi A, Williams BA, McCue K, Schaeffer L, Wold B. Mapping and quantifying mammalian transcriptomes by RNA-Seq. Nat Methods. 2008; 5(7):621-8.

33. Cheng TC. The role of lysosomes in Molluscan inflammation. Am Zool. 1983; 23:129-44. https://doi.org/10.1093/icb/23.1.129.

34. Rodrick GE, Cheng TC. Kinetic properties of lysozyme from the hemolymph of Crassostrea virginica. J Invertebr Pathol. 1974;24:41-8. https://doi.org/10. 1016/0022-2011(74)90162-1.

35. Hauton C, Hawkins LE, Hutchinson S. Response of haemocyte lysosomes to bacterial inoculation in the oysters Ostrea edulis L. and Crassostrea gigas (Thunberg) and the scallop Pecten maximus (L). Fish Shellfish Immunol. 2001;11:143-53. https://doi.org/10.1006/fsim.2000.0301.

36. Proell M, Riedl SJ, Fritz JH, Rojas AM, Schwarzenbacher R. The nod-like receptor (NLR) family: a tale of similarities and differences. PLoS One. 2008;3: e2119. https://doi.org/10.1371/journal.pone.0002119.

37. Carneiro LA, Travassos LH, Philpott DJ. Innate immune recognition of microbes through Nod1 and Nod2: implications for disease. Microbes Infect. 2004;6:609-25. https://doi.org/10.1016/j.micinf.2004.01.012.

38. Zhang SM, Loker ES, Sullivan JT. Pathogen-associated molecular patterns activate expression of genes involved in cell proliferation, immunity and detoxification in the amebocyte-producing organ of the snail Biomphalaria glabrata. Dev Comp Immunol. 2016;56:25-36. https://doi.org/10.1016/j.dci. 2015.11.008.

39. Iwasaki A, Medzhitov R. Toll-like receptor control of the adaptive immune responses. Nat Immunol. 2004;5:987-95.

40. Drickamer K, Taylor ME. Biology of animal lectins. Annu Rev Cell Biol. 1993;9: 237-64.

41. Akira S, Uematsu S, Takeuchi O. Pathogen recognition and innate immunity. Cell. 2006;124:783-801. https://doi.org/10.1016/j.cell.2006.02.015.

42. Mun S, Kim YJ, Markkandan K, Shin W, Oh S, Woo J, et al. The wholegenome and Transcriptome of the Manila clam (Ruditapes philippinarum). Genome Biol Evol. 2017;9:1487-98. https://doi.org/10.1093/gbe/evx096.

43. Gorbushin AM. Derivatives of the lectin complement pathway in Lophotrochozoa. Dev Comp Immunol. 2019;94:35-58. https://doi.org/10. 1016/j.dci.2019.01.010 
44. Kishore U, Gaboriaud C, Waters P, Shrive AK, Greenhough TJ, Reid KB, et al. $\mathrm{Clq}$ and tumor necrosis factor superfamily: modularity and versatility. Trends Immunol. 2004;25:551-61. https://doi.org/10.1016/j.it.2004.08.006.

45. Gestal C, Pallavicini A, Venier P, Novoa B, Figueras A. MgC1q, a novel C1q domain-containing protein involved in the immune response of Mytilus galloprovincialis. Dev Comp Immunol. 2010;34:926-34. https://doi.org/10. 1016/j.dci.2010.02.012.

46. Philipp EE, Kraemer L, Melzner F, Poustka AJ, Thieme S, Findeisen U, et al. Massively parallel RNA sequencing identifies a complex immune gene repertoire in the lophotrochozoan Mytilus edulis. PLoS One. 2012;7:e33091. https://doi.org/10.1371/journal.pone.0033091.

47. Jason R, Song WC. Complement and its role in innate and adaptive immune responses. Cell Res. 2010;20:34-50.

48. Ni D, Song L, Wu L, Chang Y, Yu Y, Qiu L, et al. Molecular cloning and mRNA expression of peptidoglycan recognition protein (PGRP) gene in bay scallop (Argopecten irradians, Lamarck 1819). Dev Comp Immunol. 2007;31: 548-58. https://doi.org/10.1016/j.dci.2006.09.001.

49. Su J, Ni D, Song L, Zhao J, Qiu L. Molecular cloning and characterization of a short type peptidoglycan recognition protein (cfpgrp-s1) cdna from zhikong scallop chlamys farreri. Fish Shellfish Immunol. 2007;23(3):646-56.

50. lizuka M, Nagasaki T, Takahashi KG, Osada M, Itoh N. Involvement of Pacific oyster CgPGRP-S1S in bacterial recognition, agglutination and granulocyte degranulation. Dev Comp Immunol. 2014;43:30-4. https://doi.org/10.1016/j. dci.2013.10.011.

51. Wei $X$, Yang J, Yang D, Xu J, Liu X, Yang J, et al. Molecular cloning and mRNA expression of two peptidoglycan recognition protein (PGRP) genes from mollusk Solen grandis. Fish Shellfish Immunol. 2012;32(1):178-85.

52. Tao $Y$, Yang Z, Zhang $X, W u H$. Molecular cloning and mRNA expression of the peptidoglycan recognition protein gene HCPGRP1 and its isoform HcPGRP1a from the freshwater mussel Hyriopsis cumingi. Genet Mol Biol. 2014;37:508-17.

53. Zhao J, Li C, Chen A, Li L, Su X, Li T, et al. Molecular Characterization of a Novel Big Defensin from Clam Venerupis philippinarum. PLoS One. 2010; 5(10):e13480.

54. Gueguen Y, Herpin A, Aumelas A, Garnier J, Fievet J, Escoubas JM, et al. Characterization of a defensin from the oyster Crassostrea gigas. Recombinant production, folding, solution structure, antimicrobial activities, and gene expression. J Biol Chem. 2006;281:313-23. https://doi.org/10.1074/ jbc.M510850200.

55. Adhya M, Jeung HD, Kang HS, Choi KS, Lee DS, Cho M. Cloning and localization of MCdef, a defensin from Manila clams (Ruditapes philippinarum). Comp Biochem Physiol B: Biochem Mol Biol. 2012;161:25-31. https://doi.org/10.1016/j.cbpb.2011.09.003.

56. Zhao J, Song L, Li C, Ni D, Wu L, Zhu L, et al. Molecular cloning, expression of a big defensin gene from bay scallop Argopecten irradians and the antimicrobial activity of its recombinant protein. Mol Immunol. 2007:44:3608. https://doi.org/10.1016/j.molimm.2006.02.025.

57. Yang D, Zhang Q, Wang Q, Chen L, Liu Y, Cong M, et al. A defensin-like antimicrobial peptide from the manila clam, Ruditapes philippinarum: investigation of the antibacterial activities and mode of action. Fish Shellfish Immunol. 2018;80:274-80.

58. Seo JK, Crawford JM, Stone KL, Noga EJ. Purification of a novel arthropod defensin from the American oysterCrassostrea virginica. Biochem Biophys Res Commun. 2005;338:1998-2004. https:/doi.org/10.1016/j.bbrc.2005.11.013.

59. Knappe D, Kabankov N, Herth N, Hoffmann R. Insect-derived short prolinerich and murine cathelicidin-related antimicrobial peptides act synergistically on gram-negative bacteria in vitro. Future Med Chem. 2016;8: 1035-45. https://doi.org/10.4155/fmc-2016-0083.

60. Rodriguez C, Mayo JC, Sainz RM, Antolin I, Herrera F, Martin V, et al. Regulation of antioxidant enzymes: a significant role for melatonin. J Pineal Res. 2004;36(1):1-9.

61. Aguirre J, Rios-Momberg M, Hewitt D, Hansberg W. Reactive oxygen species and development in microbial eukaryotes. Trends Microbiol. 2005;13:111-8. https://doi.org/10.1016/j.tim.2005.01.007.

62. Winterbourn CC. Reconciling the chemistry and biology of reactive oxygen species. Nat Chem Biol. 2008:4:278-86. https://doi.org/10.1038/nchembio.85.

63. Nie H, Liu L, Huo Z, Chen P, Ding J, Yang F, et al. The HSP70 gene expression responses to thermal and salinity stress in wild and cultivated Manila clam Ruditapes philippinarum. Aquaculture. 2017:470:149-56.

64. Zhao L, Shirai K, Tanaka K, Milano S, Higuchi T, Murakamisugihara N, et.al. A review of transgenerational effects of ocean acidification on marine bivalves and their implications for sclerochronology. Estuarine, Coastal Shelf Sci. 2020;235:106620. https://doi.org/10.1016/j.ecss.2020.106620.

65. Li C, Wang L, Ning X, Chen A, Zhang L, Qin S, et al. Identification of two small heat shock proteins with different response profile to cadmium and pathogen stresses in Venerupis philippinarum. Cell Stress Chaperones. 2010; 15:897-904. https://doi.org/10.1007/s12192-010-0198-6.

66. Robertsen B. Expression of interferon and interferon-induced genes in salmonids in response to virus infection, interferon-inducing compounds and vaccination. Fish Shellfish Immunol. 2008;25:351-8. https://doi.org/10. 1016/j.fsi.2008.02.004.

67. Purcell MK, Laing KJ, Woodson JC, Thorgaard GH, Hansen JD. Characterization of the interferon genes in homozygous rainbow trout reveals two novel genes, alternate splicing and differential regulation of duplicated genes. Fish Shellfish Immunol. 2009;26:293-304. https://doi.org/ 10.1016/j.fsi.2008.11.012.

68. Itsui Y, Sakamoto N, Kakinuma S, Nakagawa M, Sekineosajima Y, Tasakafujita $M$, et al. Antiviral effects of the interferon-induced protein guanylate binding protein 1 and its interaction with the hepatitis C virus NS5B protein Hepatology. 2009;50(6):1727-37.

69. Ding J, Wang R, Yang F, Zhao L, Qin Y, Zhang G, et al. Identification and characterization of a novel phage-type like lysozyme from Manila clam, Ruditapes philippinarum. Dev Comp Immunol. 2014;47(1):81-90. https://doi. org/10.1016/j.dci.2014.06.0130.

70. Zeng X, Kudinha T, Kong F, Zhang QQ. Comparative Genome and Transcriptome Study of the Gene Expression Difference Between Pathogenic and Environmental Strains of. Front Microbiol. 2019; 10(undefined):443. https://doi.org/10.3389/fmicb.2019.00443.

71. Shu CC, Wang D, Guo J, Song JM, Chen SW, Chen LL, et al. Analyzing AbrB-knockout effects through genome and transcriptome sequencing of DW2. Front Microbiol. 2018;9(undefined):307. https://doi.org/10.3389/ fmicb.2018.00307.

72. Jiang S, Luo J, Xu F, Zhang X. Transcriptome analysis reveals candidate genes involved in Gibberellin-Induced fruit setting in triploid loquat. Front Plant Sci. 2019;44:3178-86. https://doi.org/10.3389/fpls.2016.019240.

73. Zhang $X$, Wen $H$, Wang $H$, Ren Y, Zhao J, Li Y. RNA-Seq analysis of salinity stress-responsive transcriptome in the liver of spotted sea bass (Lateolabrax maculatus). PLoS ONE. 2017;12(3):e0173238. https://doi.org/10.1371/journal. pone.0173238

74. Su D, Li W, Chi H, Yang H, She X, Wang K, et al. Transcriptome analysis of the hippocampus in environmental noise-exposed SAMP8 mice reveals regulatory pathways associated with Alzheimer's disease neuropathology. Environ Health Prev Med. 2020;25(1):3. https://doi.org/10.1186/s12199-0190840-6.

75. Mortazavi A, Williams BA, McCue K, Schaeffer L, Wold B. Mapping and quantifying mammalian transcriptomes by RNA-Seq. Nat Methods. 2008;5(7): 621-8. https://doi.org/10.1038/nmeth.1226.

76. Liao Y, Smyth GK, Shi W. featureCounts: an efficient general purpose program for assigning sequence reads to genomic features. Bioinformatics. 2014;30(7):923-30. https://doi.org/10.1093/bioinformatics/btt656.

77. Song K, Li L, Zhang G. Bias and correction in RNA-seq data for marine species. Mar Biotechnol. 2017;19:541-50. https://doi.org/10.1007/s10126-0179773-5.

78. Pertea M, Kim D, Pertea GM, Leek JT, Salzberg SL. Transcript-level expression analysis of RNA-seq experiments with HISAT, StringTie and Ballgown. Nat Protoc. 2016;11(9):1650-67.

79. Yang F, Cao H, Xiao Q, Guo X, Zhuang Y, Zhang C, et al. Transcriptome analysis and gene identification in the pulmonary artery of broilers with ascites syndrome. PLoS One. 2016;11(6):e0156045. https://doi.org/10.1371/ journal.pone.0156045.

80. Yan X, Yuan F, Chen X, Dong C. Bioinformatics analysis to identify the differentially expressed genes of glaucoma. Mol Med Rep. 2015;12:4829-36. https://doi.org/10.3892/mmr.2015.4030.

81. Thomas S, Kenneth D, Livak J. Analyzing real-time PCR data by comparative CT method. Nat Protoc. 2008:3:1101-8.

\section{Publisher's Note}

Springer Nature remains neutral with regard to jurisdictional claims in published maps and institutional affiliations. 